\title{
Lipid-based nanovesicles for nanomedicine
}

\author{
N. Grimaldi, ${ }^{a, b}$ F. Andrade, ${ }^{a, c}$ N. Segovia, ${ }^{a, c}$ L. Ferrer-Tasies, ${ }^{b, a, c}$ S. Sala, ${ }^{c, a}$ J. Veciana, ${ }^{a, c}$ and N. Ventosa, ${ }^{a, c}$ \\ ${ }^{a}$ Institut de Ciència de Materials de Barcelona (ICMAB-CSIC), Campus Universitari de Bellaterra, 08193 , Cerdanyola del \\ Vallès, Spain. \\ ${ }^{b}$ Nanomol Technologies SA, Módul de Recerca B, Campus Universitari de Bellaterra, 08193, Cerdanyola del Vallès, Spain. \\ ${ }^{c}$ CIBER de Bioingeniería, Biomateriales y Nanomedicina (CIBER-BBN), Madrid, Spain.
}

Molecular self-assembly has enabled the fabrication of biologically inspired, advanced nanostructures as lipid-based nanovesicles (L-NVs). The oldest L-NVs, liposomes have been widely proposed as potential candidates for drug delivery, diagnostic and/or theragnostic applications and some liposome-based drug products have already stepped from the lab-bench to the market. This success is attributed to their ability to encapsulate both hydrophobic and/or hydrophilic molecules, efficiently carry and protect them within the body and finally deliver them at the target site. These positive features are also coupled with high biocompatibility. However, liposomes still present some un-solved drawbacks, as poor colloidal stability, short shelf-life, restricted and expensive conditions of preparation because of the inherent nature of their fundamental constituents (phospholipids). The new tools available in controlled molecules self-assembly have significantly advanced the field of L-NVs design and synthesis, and non-liposomal L-NVs have been recently developed; this new generation of nanovesicles can represent a paradigm shift in Nanomedicine: they may complement liposomes, showing their advantages and overcoming most of their drawbacks. Clearly, being still young, their rocky way to the clinic first, and then to the market has just started and it is still long, but they have all the potentialities to reach their objective target. The purpose of this review is to first present the large plethora of L-NVs available, focusing on this new generation of non-liposomal L-NVs and showing their similarities and differences with respect to their ancestors (liposomes). Since the overspread of a nanomaterial to the market is also strongly dependent on the availability of technological-scale preparation methods, we will also extensively review the current approaches exploited for L-NVs production. The most cutting-edge approaches based on compressed-fluid (CF) technologies will be here highlighted since they show the potential to represent a game-changing in the production of L-NVs, favouring their step from the bench to the market. Finally, we will briefly discuss L-NVs applications in Nanomedicine, looking also to their future perspectives.

\section{Introduction}

Nanotechnology is a buzzword of this millennium which has transformed the face of research in science and technology. Nanoparticles have been extensively proposed as alternative to conventional approaches in many technologically-advanced fields like the electronic, petrochemical, food and pharmaceutical/biomedical industry ${ }^{1-4}$. The application of nanotechnology to the biomedical field gave origin to the concept of Nanomedicine, becoming a highly studied field ${ }^{5-10}$. According to the European Science Foundation, Nanomedicine is the science and technology of diagnosing, treating and preventing disease and traumatic injury, of relieving pain, and of preserving and improving human health, using molecular tools and molecular knowledge of the human body ${ }^{11}$. In the pharmaceutical industry, nanomaterials and especially nanoparticles have found their application in (i) the rescue of some drugs, presenting promising therapeutic value, but not exploited because of the difficulties inherent to their formulation/compounding; (ii) the "make-over" of drugs already used in clinical practice 12,13; (iii) administration of biopharmaceuticals (therapeutic proteins, DNA, RNAs, antisense ODNs, cells), which are an emerging generation of delicate and challenging therapeutics ${ }^{14,15}$. In general, nanoparticles based formulations can overcome the drawbacks of the conventional ones; they allow the administration of drugs in a more effective and safe manner by increasing their solubility and stability, targeting specific organs and tissues, reducing their rapid clearance from the body and their side effects. Among all the proposed nanoparticles, such as inorganic nanoparticles, polymeric nanoparticles, carbon nanotubes and nanogels ${ }^{16-21}$, lipid-based nanovesicles (L-NVs) have been intensively investigated, because from the very beginning they have shown excellent performances.

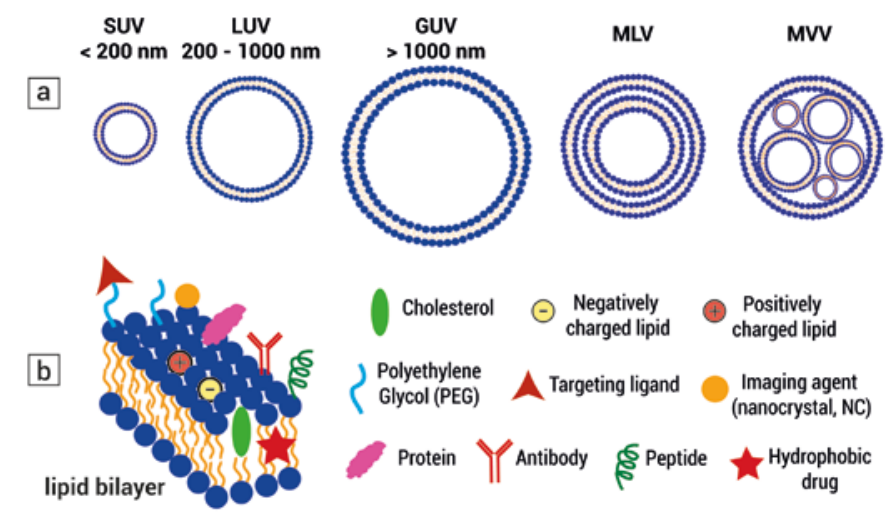


Figure 1. Schematic representation of lipid-based vesicles. a) classification of vesicles regarding their size and lamellarity; b) structure of the vesicles bilayer (left side) and examples of (bio)-actives to be physically encapsulated or chemically conjugated.

L-NVs are regarded as small sphere-shaped bilayered vesicles containing lipids in its constitution. Usually, vesicles are broadly classified into small unilamellar vesicles/nanovesicles (SUVs, size $<200 \mathrm{~nm}$ and single bilayer), large unilamellar vesicles (LUVs, size ranging from $200-1000 \mathrm{~nm}$ and single bilayer), giant unilamellar vesicles (GUVs, size > $1000 \mathrm{~nm}$ and single bilayer), multilamellar vesicles (MLVs, consisting of several concentric bilayers) and multivesicular vesicles (MVVs, composed by several small vesicles entrapped into larger ones) (Figure 1a). The surface of the vesicles can be easily functionalized with different ligands (Figure 1b), allowing the production of smart, multifunctional systems. In general, many parameters need to be controlled when nanocarriers are synthesized and among them the size, the morphology and the surface properties are the most relevant since they govern the interactions among nanocarriers and cells. Furthermore, the membrane organization also needs to be taken into account in the case of L-NVs. Smaller size (100-200 nm), are usually requested as well as high homogeneity in size and structure. For this reason, SUVs have attracted great attention in the drug delivery field since they have the right compromise of size: they are big enough to avoid the rapid clearance through the kidneys and small enough to present a minimal uptake by the mononuclear phagocytic system, facilitating their longer circulation lifetime in the body and hence a higher possibility to reach the target cells ${ }^{22}$. Moreover, SUVs can easily accumulate within tumors through the so-called enhanced permeability and retention (EPR) effect and thereby be applied in cancer therapy ${ }^{23,24}$. On the other hand SUVs, compared to MLVs or MVVs, allow a more accessible and homogeneous membranes functionalization and this finally turns in a homogeneous and sharp response of the system to an external stimulus, i.e. allowing the homogeneous release of the drug at the target site, if the vesicles are functionalized with a drug. Among lipid-based SUVs, liposomes have been the first ones developed and they have quickly stepped from the lab-bench to the clinic and finally they have imposed their presence on the market. Indeed, some liposomal-based therapeutic systems have been already approved by regulatory agencies and others are nowadays under clinical evaluations ${ }^{15,25,26}$. Liposomes were discovered by Bangham and co-worker 50 years ago, and are constituted by an aqueous core enclosed by single or multiple concentric phospholipid bilayers (Figure 2a). The first formulation of liposomes was composed by natural phospholipids ${ }^{27}$. Nowadays, liposomes are composed by naturally and/or synthetic phospholipids, such as phosphatidylcholine (PC), phosphatidylethanolamine (PE), phosphatidylserine (PS), and phosphatidylglycerol (PG) ${ }^{28-30}$. Liposomes have several advantages as drug delivery systems (DDS) due to their high biocompatibility ${ }^{31}$, and their ability to entrap both hydrophilic and hydrophobic drugs into their aqueous core or in their lipid bilayers, respectively ${ }^{32}$. However, they show some drawbacks as poor colloidal and chemical stabilities, rapidly clearance from the blood after intravenous administration ${ }^{33}$, high permeability of their membranes causing leaks of the entrapped drugs due to the intrinsic rotational freedom of the phospholipids, etc. In order to overcome these problems, new liposomal-based nanovesicles have been developed. For example, surface-modified liposomes by the means of glycolipids, mimicking the erythrocyte membrane, or with hydrophilic synthetic polymers, such as poly(ethylene glycol) (PEG) ${ }^{34}$ (stealth liposomes), have been synthesized and they have shown a longer circulation time. Or in order to improve the physical stability of liposomes, cholesterol (Chol) has been added as additional component of the lipid bilayers, since it can enhance membrane rigidity and in vitro and in vivo stability ${ }^{35,36}$. As regards their poor colloidal stability and short shelf-life, many attempts have been done, but without success ${ }^{37}$. In fact, liposomes correspond to a metastable state, which is achieved by the input of external energy (e.g., sonication or mechanical filtration). The stability of these structures is kinetically limited because the phospholipids are highly insoluble, thus they have the tendency to aggregate (equilibrium state) ${ }^{38,39}$. Usually liposomes are stored as dry products which can be reconstituted prior to administration 40. All the mentioned restricted conditions of preparation and storage, besides the elevated price of phospholipids have addressed the research towards new vesicular formulations, made of cheaper and more stable membrane components ${ }^{41-45}$. New findings in molecular self-assembly made possible to design and synthesize new biologically inspired, advanced, almost "tailor-made" (i.e. nanovesicles suited for a particular purpose) L-NVs. For instance, it has been discovered that certain lipids can self-assemble in appropriate conditions with surfactants ${ }^{43,46-48}$, polymers ${ }^{49-51}$, polypeptides ${ }^{52-54}$, and furellene-based derivatives ${ }^{55-57}$, leading to a new generation of non-liposomal vesicle-like structures containing at least one natural or synthetic lipid in their composition ${ }^{58}$. The driving force for the self-assembly through weak, noncovalent interactions of such molecules in water is the inherent hydrophobic character of the lipids. Depending on their composition, nanovesicles showing various physicochemical properties (size, charge density, functionality, morphology and lamellarity) and drug encapsulation efficiencies can be produced ${ }^{59-61}$. Moreover, multitasking nanocarriers can be generated with specific dual or multiple mode functions, such as active targeting by incorporating targeting ligands, prolonged circulation in the blood, and triggered release of the drug under local stimuli (like $\mathrm{pH}$, temperature, enzymatic changes) ${ }^{62-64}$. Many papers and reviews have been published, describing the oldest representatives of L-NVs, i.e. liposomes ${ }^{20,28,31,58,65-68}$. Conversely, the purpose of this review is to provide a description of the new generation of non-liposomal L-NVs, since they are still not well-known. They have already demonstrate huge potential, especially at pre-clinical stage ${ }^{69-74}$ but in order to be overspread to the market, they need to be translated in pharmaceutical products, both showing excellent performances in vivo and providing manufacturing processes viable at industrial scale for their production. Because of that, we will also review the current synthetic methods for L-NVs production, highlighting the technologies that can support non-liposomal L-NVs in their rocky way to the market. Among these, we will extensively describe 
compressed fluids (CF)-based technologies since we believe they can represent a game-changing in L-NVs production. In fact, CFbased technologies have already shown their potential in terms of granting high throughput of homogeneous, high quality L-NVs and high compliance with the constraints imposed by Good Manufacturing Practices (GMP). Furthermore, it has been assessed that they are easily scalable at industrial level and they have been recognized as green technologies, making them even more appealing for the pharmaceutical industry. The last part of the review will be dedicated to the currently biomedical applications of L-NVs in Nanomedicine, finally looking to their future perspectives. It is worth to point out here that even though liposomes are not meant to be the main characters of this review, because they are the "oldest" and "more developed" L-NVs, they will be often re-called in this review and used either as "model" or "antimodel" in the comparison with non-liposomal L-NVs.

\section{Non-Liposomal Lipid-Based Nanovesicles: Classification}

In order to describe the most important types of non-liposomal L-NVs, we have divided them in different groups depending on their membrane components, where at least one of them is a natural and/or a synthetic lipid. The most important properties of each system here described are reported in Table 1.

\section{Niosomes}

Niosomes (Figure 2c), or non-ionic surfactant vesicles, have gained increasing scientific attention as drug delivery systems with respect to conventional liposomes (Figure 2a), due to the use of surfactants in their formulation, which are cheaper and more stable alternatives than phospholipids. Niosomes are prepared by mixting nonionic surfactants, such as alkyl ether, alkyl esters or alkyl amides, fatty acids and amino acid compounds, with or without Chol or other lipids and then, subsequently hydrating the mixture ${ }^{43,46,75}$. The formation of such vesicle-like structures depends on the hydrophilic-lipophilic balance (HLB) of the surfactant, the chemical structure of the components and their geometry and aspect ratio ${ }^{46,76}$. Addition of Chol to these structures improves the rigidity of the bilayer, reducing the permeability of vesicles to encapsulated drugs, preventing thereby the leakages, and enhancing the drug encapsulation ${ }^{59,60,64}$. The size range of niosomes includes nano and submicron sizes, and the vesicle structures can be unilamellar or multilamellar ${ }^{77}$. Owing to vesicle structure, niosomes are able to entrap both hydrophilic and hydrophobic drugs, as liposomes do. Interestingly, surfactants can be easily chemically modified allowing a high versatility of vesicular structures. Niosomes are quite stable at least for few months depending on their membrane components and additive agents ${ }^{78,79}$. Moreover, the high chemical stability of surfactants, compared with phospholipids, makes niosomes purification, handling and storage much more easier ${ }^{80-83}$. Niosomes formulations have been shown good in vitro and in vivo results for the delivery of both pharmaceuticals and biopharmaceuticals ${ }^{43,84,85}$. For example, promising transfection efficiencies has been achieved with niosomes loaded with plasmid DNA after subretinal, intravitreal and brain injections in rats ${ }^{70}$. In another study, insulin permeability has been evaluated by Caco-2 cell monolayer, and it has been observed an enhancement of insulin permeation up to 4-fold by niosomal formulation compare to insulin alone ${ }^{79}$. Also, niosomes loaded with glucocorticoids, such as beclomethasone dipropionate (BDP), show promising results in vitro for the treatment of inflammatory lung diseases. Human lung fibroblast cells showed an increase of the drug anti-inflammatory activity after treatment with niosomal formulation ${ }^{85}$. Despite the promising results achieved both in vitro and in vivo, niosomes have some disadvantages related to their poor physical stability and sterilization issues ${ }^{86,87}$.

Table 1: Examples of non-liposomal L-NVs and their main characteristics.

\begin{tabular}{|c|c|c|c|c|}
\hline System & Composition & $\begin{array}{c}\text { Size } \\
\text { Lamellarity }\end{array}$ & Stability & $\begin{array}{c}\text { Example of } \\
\text { preclinical study } \\
\text { (refs) }\end{array}$ \\
\hline Niosomes & Chol/Non Ionic Surfactants & $\begin{array}{l}\text { Nano and sub-micron range } \\
\text { Unilamellar \& multilamellar }\end{array}$ & $\begin{array}{l}\text { Short-term stability } \\
\text { (few months) }\end{array}$ & $\begin{array}{l}\text { In vitro } \\
\text { In vivo }^{70}, 79,88,85\end{array}$ \\
\hline Transfersomes & Phospholipids/Surfactants & $\begin{array}{l}\text { Nano and sub-micron range } \\
\text { Unilamellar \&multilamellar }\end{array}$ & $\begin{array}{c}\text { Short-term stability } \\
\text { (few months) }\end{array}$ & $\begin{array}{l}\text { In vitro }{ }^{42,89-91} \\
\text { In vivo }\end{array}$ \\
\hline Ethosomes & Phospholipids/Alcohols & $\begin{array}{l}\text { Nano and sub-micron range } \\
\text { Unilamellar \&multilamellar }\end{array}$ & $\begin{array}{c}\text { Short-term stability } \\
\text { (few months) }\end{array}$ & $\begin{array}{l}\text { In vitro }{ }^{69,92-94} \\
\text { In vivo }^{69}\end{array}$ \\
\hline Sphingosomes & Sphingolipids/Chol & $\begin{array}{l}\text { Nano and sub-micron range } \\
\text { Unilamellar \& multilamellar }\end{array}$ & $\begin{array}{l}\text { Long-term stability } \\
\text { (several months) }\end{array}$ & $\begin{array}{l}\text { In vitro } \\
\text { In vivo } \\
95,96\end{array}$ \\
\hline Ufasomes & Fatty Acid/Surfactants & $\begin{array}{l}\text { Nano and sub-micron range } \\
\text { Unilamellar \& multilamellar }\end{array}$ & $\begin{array}{l}\text { Short-term stability } \\
\text { (few months) }\end{array}$ & $\begin{array}{l}\text { In vitro }{ }^{97-99} \\
\text { In vivo }^{99}\end{array}$ \\
\hline
\end{tabular}




\begin{tabular}{|ccccc|}
\hline \multirow{2}{*}{ Pharmacosomes } & Drug/ Phospholipids & Nano and micron range & $\begin{array}{c}\text { Short-term stability } \\
\text { (few months) }\end{array}$ & $\begin{array}{c}\text { In vitro }{ }^{100,101} \\
\text { In vivo }{ }^{101}\end{array}$ \\
\hline \multirow{2}{*}{ Virosomes } & Phospholipid/ Viral envelope & Nano and sub-micron range & Short-term stability & In vitro ${ }^{73,102-104}$ \\
& proteins & Unilamellar \& multilamellar & (few months) & In vivo ${ }^{73,102-105}$ \\
\hline \multirow{2}{*}{ Quatsomes } & Chol/Cationic Surfactants & Nano range & Long-term stability & In vitro ${ }^{74}$ \\
& & Unilamellar & (several years) & \\
\hline
\end{tabular}

\section{Transfersomes}

Liposomes as well as niosomal systems have showed low skin penetration due to the breaking of vesicles, leakage of the encapsulated drug, aggregation and fusion of the vesicles. To overcome such drawbacks new vesicular systems, called transfersomes, have been recently developed. Transfersomes were introduced in the early 1990s as a highly deformable - elastic or ultraflexible - vesicular systems, which are able to penetrate the mammalian skin intact when applied under non-occlusive conditions ${ }^{106}$. Transfersomes are composed mainly by phospholipids (such as soya PC, egg PC, dipalmityl PC, among others) and surfactants (such as span 80 , tween 80 , sodium cholate, among others) as edge activators (Figure 2 b) ${ }^{47,48}$. Usually these edge activators are single chain surfactants that have the role to produce higher radius of curvature, destabilizing the lipid bilayer of vesicles, and thus increasing its deformability. Transfersomes size are in the nano and sub-micron range, and regarding lamellarity vesicles are unilamellar ${ }^{90,107}$. These new kind of vesicles, are good candidates for transdermal delivery of both low and high molecular weight drugs, due to their high deformability allowing them to penetrate the skin by squeezing themselves along the intracellular sealing lipid of the stratum corneum 91,108-111. For example, transfersomal gel loaded with 5-fluorouracil, an antineoplastic drug, showed promising results in vivo for the treatment of skin cancer. The gel containing the transfersomal formulation showed better skin deposition and skin penetration than the drug commercially available, without any irritation of the skin after treatment ${ }^{112}$. However, transfersomes formulations have some limitations, like their poor chemical stability due to oxidation, and the lack of purity of natural phospholipids ${ }^{113}$.

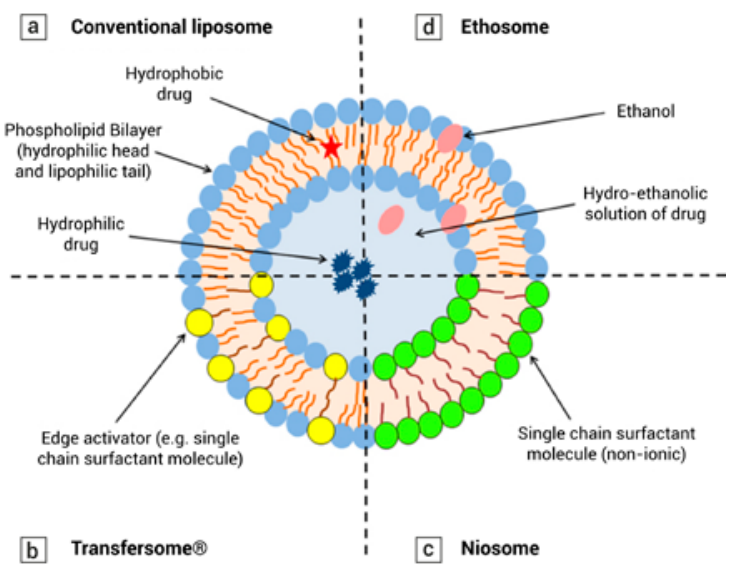

\section{Ethosomes}

Ethosomes are another recently developed vesicular systems able to penetrate the mammalian skin when applied both under occlusive and non-occlusive conditions ${ }^{110,114-116}$.

Figure 2. Schematic representation of various types of L-NVs. (A) Conventional liposomes; (B) Transfersomes; (C) Niosomes; and (D) Ethosomes. Reproduced from Ref. 117 with permission from Frontiers Media S.A.

As transfersomes, ethosomes are composed by phospholipids and an edge activator, based in this case on alcohols such as ethanol or isopropyl alcohol, used at high concentrations (Figure $2 \mathrm{~d}$ ) ${ }^{118}$. Ethosomes size can be modulated from nano to micron range, and can be obtained either unilamellar or multilamellar vesicles ${ }^{118,119}$. The high penetration achieved with these new vesicular systems are not well understood, although the high permeation is attributed to the high content of alcohols, since ethanol is a well know penetration enhancer that affects the intercellular region of the stratum corneum ${ }^{120}$. Several works using ethosomes as carriers have been shown good results both in vitro and in vivo ${ }^{69,92-94}$. For example, ethosome formulation containing psoralen has showed promising results for the treatment of vitiligo and psoriasis ${ }^{121}$. Transdermal delivery with the ethosomal formulation showed increase permeation and skin deposition of psoralen ${ }^{122}$.

\section{Sphingosomes}

The low stability of vesicular systems, such as liposomes and niosomes, has also prompted the researchers to develop other new vesicular system with improved stabilities, called sphingosomes. These new vesicular systems are composed by natural or synthetic sphingolipids and/or Chol. Sphingosomes can have vesicles size from nano to sub-micron range, and the membrane lamellarity include both unilamellar and/or multilamellar ${ }^{123}$. The most commonly used sphingolipids are hexadecasphinganine, sphinganines, lysosphingomyelins, lysoglycosphingolipids, glucuronosphingolipids, phosphoglycosphingolipids, among others. Sphingosomes show several advantages that include better resistance to hydrolysis than liposomes and better drug retention. Sphingosomes have showed promising results in vitro and in vivo for the delivery of several drugs ${ }^{124,125}$. For example, sphingosomes loaded with vinorelbine as an anti-mitotic agent have showed promising results in vivo, improving the drug 
retention, and also increasing their antitumor activity ${ }^{96}$. In addition, they can be administrated by different routes, such as intravenous, intramuscular, subcutaneous, and intra-arterial. Also, the vesicular membrane of sphingosomes can be tuned with specific ligands to achieve active targeting. However, these vesicular systems show some limitations both related to their cost, because sphingolipids are very expensive, and to their poor entrapment efficiency ${ }^{113}$.

\section{Ufasomes}

Ufasomes were first described in 1973 by Gebicki and Hicks, as vesicular systems composed by unsaturated fatty acids such as oleic acid and linoleic acid. Nowadays these vesicles are also made of saturated fatty acid such as octanoic acid and decanoic acid along with some surfactants ${ }^{126}$. Ufasomes form vesicles with size between nano and sub-micron range, and can be unilamellar and/or multilamellar ${ }^{126}$. Ufasomes have some advantages over convention liposomal formulations, since they show an improved stability, better entrapment efficiencies for both hydrophilic and hydrophobic drugs, and their membrane components are cheaper and more available ${ }^{127-129}$. Ufasomes are therefore potential carriers for topical delivery of pharmaceuticals and biopharmaceuticals $97-99,130$. For example, ufasome gel formulations loaded with dexamethasone as anti-inflamatory drug showed promising results in vivo after topical admimistration in Carrageenan induced rat paw edema model. The transdermal permeation of the drug-loaded ufasome gel was higher than the plain drug and plain gel. Moreover, a significant reduction of edema was observed, when drug-loaded ufasome gel was used, compared to the commercial product. Nevertheless, ufasomes have some issues related to their skin toxicity and their low entrapment efficiency of hydrophilic drugs ${ }^{98,130}$.

\section{Pharmacosomes}

Pharmacosomes are colloidal dispersions composed mainly by phospholipids, where drugs are covalently bound to the lipid ${ }^{131,132}$. Pharmacosomes are also referred as phytosomes, when the drug is an herbal active ingredient ${ }^{133,134}$. Pharmacosomes were developed in order to improve the encapsulation efficiency of polar drugs, which are difficult to encapsulate with high efficiencies in conventional liposomal formulations ${ }^{132}$. These colloidal dispersions can exist as vesicular, micellar or hexagonal assemblies, depending on the chemical structure of the drug-lipid complex, and the size of the assemblies obtained are in the nano and micro range ${ }^{131}$. The physicochemical stability of pharmacosomes depends mainly on the physicochemical properties of the drug-lipid complex ${ }^{135}$. Pharmacosomes can pass through biomembranes efficiently and possess several advantages over the vesicular systems previously described, since the drug is covalently bounded to the lipid, the encapsulation efficiency is increased, the leakage of drugs is avoided, there is no need of additional steps to eliminate the free drug, and the drug release is not affected by the membrane fluidity ${ }^{136,137}$. Several drugs like taxol, amoxicillin, dermatan sulphate have shown increased therapeutic effect when formulated within pharmacosomes ${ }^{131}$.

\section{Virosomes}

Virosomes are hybrids of liposomes and viruses, which integrate fusogenic viral envelope proteins into the lipid membrane of liposomes ${ }^{138,139}$. Virosomes form vesicles with size in the nano and sub-micron range, and can be unilamellar and/or multillamellar. Virosomes are promising candidates for the delivery of both pharmaceuticals and biopharmaceuticals, since the fusogenic viral proteins allow them to penetrate into cells, and escape from the endosomes, delivering their cargo directly into the cytoplasm of the cells ${ }^{140,141}$. Several works have been shown promising results both in vitro and in vivo using virosomes as carriers ${ }^{102,142-144}$. Moreover virosomes have been used as vaccine carriers and as adjuvant systems, since they have shown to improve cell-mediated and humoral immune response, generating long-term immunity against pathogens. For example, virosomes loaded with specific melanoma-associated antigen, gene or RNA induce protective immunity in a mouse-melanoma model ${ }^{145}$. Despite all the advantages that virosomes have showed, safety concerns are related with their use since the viral proteins produce some immunogenicity; additionally, they have shown poor stability ${ }^{146}$.

\section{Quatsomes}

Quatsomes are unilamellar nanovesicles constituted by quaternary ammonium surfactants and sterols in defined molar ratios 147,148 . These colloidal structures are stable upon long storage such as several years, their morphology do not change upon rising temperature or dilution, and they show outstanding vesicle to vesicle homogeneity regarding size, lamellarity and membrane supramolecular organization ${ }^{147,149,150}$. It is important to highlight that the unilamellarity of quatsome-like structures and their homogeneous morphology make these systems ideal for the precise functionalization of their membranes, which is very important for a robust and efficient drug targeting ${ }^{151-153}$. Another important characteristic of quatsomes is that their membrane components are not expensive and are available at pharmaceutical grade. For instance, the surfactants forming the quatsome membrane are widely used as disinfectants, algaecides, preservatives, detergents and antistatic components ${ }^{154}$. This confers to quatsomes an additional antibacterial feature ${ }^{74}$. Therefore quatsomes fulfill the structural and physicochemical requirements to be a potential encapsulation platform for site specific delivery of both hydrophilic and lipophilic therapeutic and diagnostic actives. These vesicular systems are promising alternative to cationic vesicles prepared with pure cationic lipids, which have showed high cytotoxicity and lower stabilities ${ }^{155,156}$. Quatsomes-like structures have been formed using different quaternary ammonium surfactants such as cetrimonium bromide (CTAB), myristalkonium chloride (MKC) and cetylpyridinium chloride (CPC) and different sterols such as cholesterol and $\beta$-sitosterol ${ }^{150}$. In a recent study, quatsomes were evaluated for their antimicrobial 
activity in an in vitro S. aureus biofilm model. Quatsomes prepared with an antiseptic quaternary ammonium compound CPC and Chol have showed good anti-biofilm capacity without no adverse effect on the cells ${ }^{74}$. Furthermore, it is worth mentioning that recently, quatsome-like structures have been produced using single-chain anionic surfactants instead of quaternary ammonium surfactants.

\section{Methods of preparation}

Physico-chemical properties of nanovesicles, including size, morphology, lamellarity as well as encapsulation efficiency (EE) are of utmost importance in order to achieve optimal performances in their final application as biofunctional materials. In general, these properties are strongly affected by the system composition and by the synthetic approaches exploited for their production. In the literature several methods for preparing lipid-based nanoparticles are described and they are usually categorized as conventional or novel. Generally, conventional approaches are easy preparation methods, especially at laboratory scale, but they usually fail when scaled-up up to industrial level. Complex, time- and chemical-consuming purifications are usually required in order to remove all the agents used in the phase of production and this, in turn slows down the production chain and raise up the processing costs, making conventional strategies not reliable at industrial level. Other issues are related to the harsh conditions applied during the production. Thus, often high mechanical stress and temperature are necessary during their processing, which can result in the degradation of labile biomolecules, such as proteins, enzymes, nucleic acids. Furthermore, the control over materials properties is not fully reliable as well as the reproducibility among different batches. Finally, the environmental constraints on production process are nowadays more restrictive, forcing the industries to drive towards more efficient and eco-friendly manufacturing process. For all these reasons, new manufacturing processes have been developed in the last years using techniques based on microfluidic or CF technologies, among others. These approaches are easy to scale-up, but can require special equipment, which in turn can rise up the costs. Financial aspects are also needed to be evaluated case-bycase ${ }^{157,158,67}$. In the following, the most used conventional and novel approaches will be presented, with a stronger emphasis on novel approaches exploiting CF-based technology. Most of the examples here presented will refer to liposomes, because only few examples of non-liposomal lipid-based vesicles are available in the literature. However a general trend can be observed: all these preparation methods may be exploited for the production of non-liposomal nanovesicles. In Table 2 the advantages and disadvantages of the various preparation methods here described are reported.

Table 2. Advantages and disadvantages of nanovesicles preparation methods.

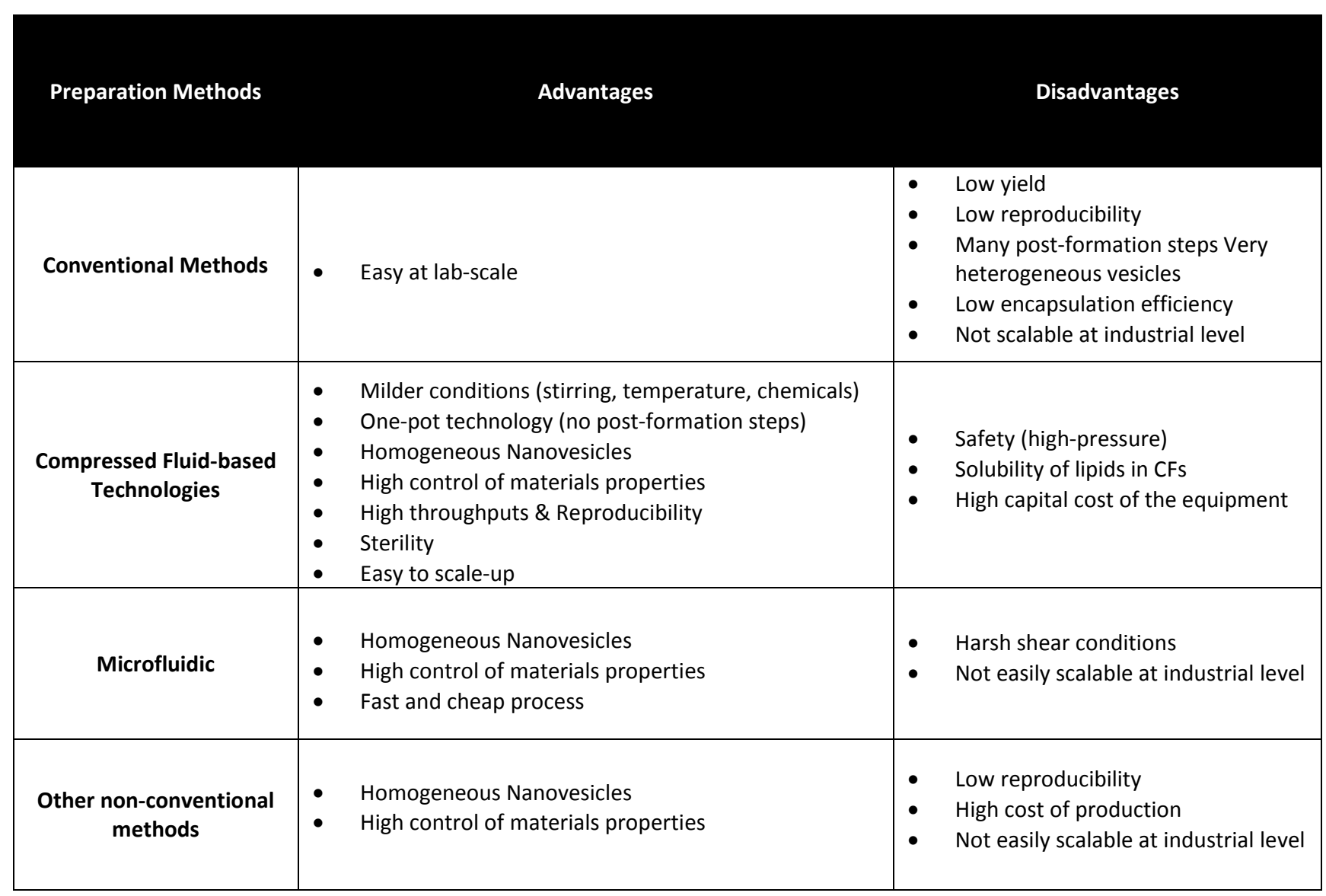


Conventional methods for vesicles production consist of a production step, during which vesicles are formed as dispersion in aqueous phase, and a few postformation steps, during which the desired structural characteristics, in terms of size, morphology and lamellarity, are achieved. There is a wide variety of conventional methods to prepare liposomes, including thin-film hydration, reverse-phase evaporation, solvent injection, and detergent dialysis ${ }^{65,159-161}$ With the majority of these techniques, after the production step, big LUVs, MLVs and GUVs are obtained. In these methods the self-assembly of lipid vesicles typically occurs within environments with characteristic dimensions of millimeters or centimeters, which results in local concentration fluctuations of lipids and payloads, i.e. heterogeneity. In order to alter particle size and minimize the polydispersity, postformation steps are needed such as sonication ${ }^{162}$ extrusion ${ }^{163-165}$, and high-pressure homogenization ${ }^{166,167}$ methods to end up with a homogeneous dispersion of SUVs. A schematic representation of the conventional processes is reported in Figure 3. Mechanical forces are applied for disrupting large MLVs into small membrane patches that ultimately form SUVs. The need for using additional mechanical processing limits to a great extent the application of conventional methods for the encapsulation of fragile molecules due to the extreme conditions usually applied. The thin lipid film hydration method was developed by Bangham et al. for liposomes production and it has been extensively used since then for the production of other L-NVs and micelles ${ }^{168,169}$. Lipids are dissolved in an organic solvent, which is then evaporated. A thin lipid film is created in a round-bottom flask and the complete removal of the solvent is achieved by freeze-drying. The nanovesicles are formed after re-hydration of this thin-film with an aqueous solution. Multiple freeze/thaw cycles are often requested in the latter step. Depending on the conditions of rehydration, nanovesicles with different physico-chemical properties are obtained.

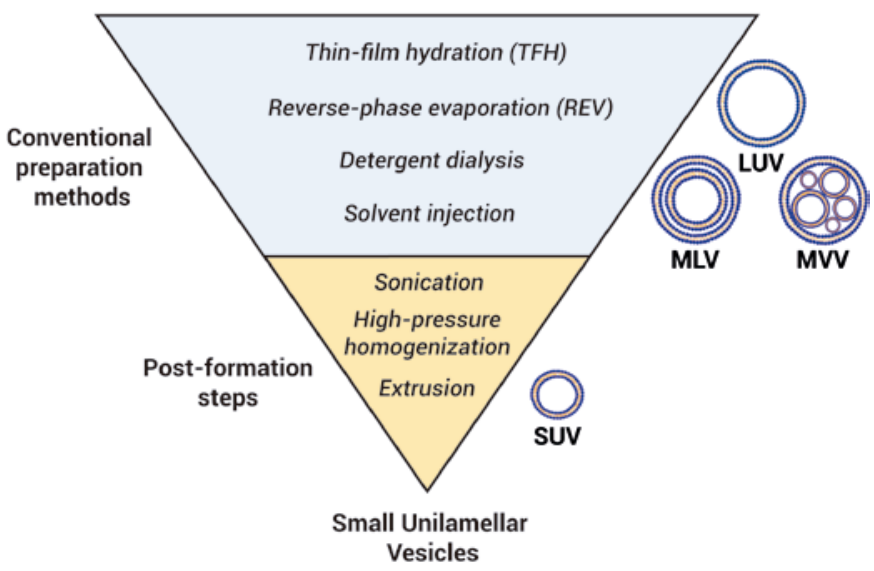

Figure 3. Schematic representation of the most common conventional synthetic approaches for L-NVs production.

As already mentioned, in order to obtain particles with smaller sizes and higher homogeneity, some additional steps need to be performed ${ }^{170}$. In Figure 4 it is shown a schematic representation of the thin film hydration method. Although it is a simple technique at laboratory scale, it is not easily scalable to industrial level since its reproducibility and yield are low, requiring multiple time- and energy-consuming steps to reach the final product. Another technique extensively used for L-NVs production is the reverse phase evaporation method. In this method the lipids are first dissolved in an organic solvent, which is then evaporated in order to form a lipid film. This film is then re-dissolved in ether or isopropyl ether. Afterwards, an aqueous phase, carrying the drug to be loaded in, is added to the organic phase and the two phases are mixed where inverted micelles or water-in-oil emulsion are formed.

The organic solvent is gently evaporated under a reduced pressure and a dispersion of nanovesicles in water is obtained ${ }^{160}$. Sometimes a further purification step is requested, in order to completely remove the organic solvent. The reverse-phase evaporation method presents higher encapsulation efficiencies than thin film hydration; however it is limited by the solubility of the lipids in the organic phase and the subsequent removal of the solvent from the final preparation. The solvent injection technique has been also exploited in order to form L-NVs. In this case an organic solution of lipids is directly injected in an aqueous solution. The rapid dilution of the organic solvent in the aqueous phase causes the formation of nanovesicles. Depending on the solvent used, the technique is slightly modified. For example when ether is used, the aqueous phase is warmed up to 60 o $\mathrm{C}$ before performing the injection. This technique really often leads to heterogeneous vesicles, both in terms of size, morphology and lamellarity ${ }^{171,172}$. Finally, in the detergent depletion method, the lipids are first dissolved into micelles, which act as a template and then an aqueous phase is added. When the surfactant is removed, the lipids start to coalesce and the vesicles are formed. Usually large unilamellar vesicles are formed with this method and problems associated with detergent removal, which include low trapping efficiency and length of preparation, limit the use of detergent-based techniques in producing LUVs ${ }^{173-175}$.

\section{Novel Preparation Methods}

Compressed Fluid-based Technologies Compressed Fluid (CF)-based technologies have recently gained importance for the

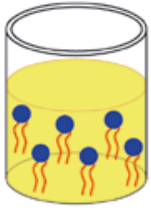

lipid solution

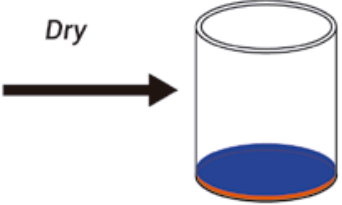

lipid film

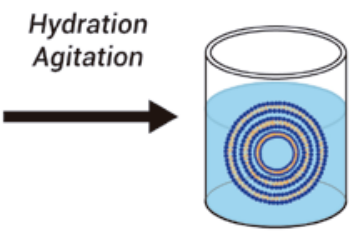

MLVs / MVVs
Freeze/thaw cycles

$$
\text { Extrusion }
$$

Sonication

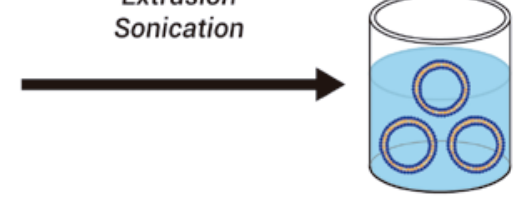

SUVs / LUVs 
production of L-NVs by (i) showing high throughput of high quality, homogeneous products; (ii) being a promise for the industrialization of such materials and (iii) accommodating the principle of green chemistry.

The unique features of CFs in terms of gas-like mass transfer properties and liquid-like solvent power together with their pressure-tunability are the keys for the successful performances of CF-based technologies. ${ }^{176,177}$ In fact, the prominent properties of CFs can be tuned by the mean of the pressure: pressure variations are mechanical perturbations that travel at the speed of sound, propagating quickly and homogeneously across the medium leading to large but uniform modifications of the fluid density and solvent power. When used as a trigger for nanoparticles formation, this fast and homogeneous modification of the fluid properties favours the achievement of high quality, uniform nanomaterials without the need for postformation steps as in conventional methods $149,159,176,178,179$. Such feature is missed in other approaches, where the triggers for nanoparticles formation are changes in the temperature or composition, which do not propagate quickly and homogeneously within the medium, causing gradients of concentration inside the reactor and leading to heterogeneous nanoparticles. CF-based technologies allow to reduce the high mechanical stress due to the high stirring as well as the high operating temperatures used in conventional processes, which in turn can degrade labile compound ${ }^{177,178,180}$. Moreover, the extensive use of organic solvents or other delicate chemicals is reduced by CFs, improving the toxicological profile of the particles produced; CF-based technologies are often one-pot production technologies and they can also provide sterile operating conditions ${ }^{159,181}$. The most widely used $\mathrm{CF}$ is $\mathrm{CO}_{2}$, which is nontoxic, non-flammable and easy recyclable. The moderate critical parameters of $\mathrm{CO}_{2}(\mathrm{Pc}=7.4$ $\mathrm{MPa} ; \mathrm{Tc}=304.1 \mathrm{~K}$ ) together with its low price and high availability make also $\mathrm{CO}_{2}$-based technology very attractive from an economical perspective. Most of the methods using compressed $\mathrm{CO}_{2}$ for L-NVs production involve the formation of a mixture of this dense gas, the vesicle membrane constituents, and an organic solvent at a certain pressure and temperature; vesicles are usually produced upon contact between this organic phase and an aqueous phase. Various CF-based technologies have been developed for the generation of L-NVs by changing the experimental procedure, parameters, and equipment resulting in a large variety of vesicular systems with differentiated characteristics. Generally, CF can act either as a solvent or as anti-solvent or as co-solvent, depending on the solubility of the solutes in the $\mathrm{CF}^{176,181,182}$. More in detail, the CF is used as solvent when all the components are likely soluble in it; in this case, the organic solvent acts as a co-solvent, when present. When the CF is used as anti-solvent, it means that the components are not soluble in it, so first they are dissolved in the organic solvent and then the $\mathrm{CF}$ is added to the mixture for triggering the precipitation of solutes. Finally, when the CF is used as a co-solvent, all the components are dissolved in a mixture of the organic solvent and the $\mathrm{CF}$, which in turn increases the solubility of the solutes in the organic solvent ${ }^{159,176,178,179}$. In Table 3, the CF-based technologies here reviewed are summarized, by defining the role of CF and if the organic solvent is present or not. Also, the typical operation conditions used are reported, as well as the kind of SUVs produced. As far as we know, Depressurization of an Expanded Liquid Organic Solution-SUSPension method (DELOS-SUSP) is the only CFbased technology that have been already used for the production of non-liposomal L-NVs. In particular, a variety of Quatsomes have been generated by exploiting this method. The injection and decompression methods described by Castor and Chu in 1994 ${ }^{183}$ have been the first CF-based techniques developed for the formation of liposomes (Figure 5). While in the injection method, a mixture of lipid, organic co-solvent, and compressed gas is injected through a nozzle into an aqueous solution, the decompression method involves a mixture of lipid, organic co-solvent, compressed gas, and aqueous solution being decompressed into air through a nozzle to form the vesicles. The major distinction between the two methods is the "place" in which occurs the contact between the organic and the aqueous phase. The authors have studied the effect of the nozzle size on the liposomes size and they have found that the smaller is the size of the nozzle, the smaller are the liposomes. The injection method is more suitable for the processing of labile compound because of the absence of high shear forces. The authors claim that the injection and decompression methods are capable of producing substantially solvent-free, sterile and pharmaceutical grade vesicles with narrow particle size distribution ${ }^{184}$. The liposomes generated by these methods have also shown excellent colloidal stability over a period of 6 months ${ }^{185}$. However, for the clinical development of liposomal drugs, a shelf-life of more than 12 months needs to be proved. This method has shown to be well suited both for hydrophobic and hydrophilic drugs encapsulation, such as taxoids, doxorubicin, michellamine B, vincristine and cisplatin ${ }^{186}$

Table 3. Summary of CF-based technologies reviewed. $\mathrm{CO}_{2}$ role, presence or not of any organic solvent, temperature $(\mathrm{T})$ and pressure $(\mathrm{P})$ and kind of SUVs produced are reported.

\begin{tabular}{|ccccc|}
\hline Method $^{(\text {year, ref) }}$ & CO $_{2}$ role & Org. Solv. & T (oC); P (MPa) $^{\text {SUVs }}{ }^{\text {(refs) }}$ \\
\hline Injection method $^{(1994,183)}$ & Solv. & Yes & $60 ; 20$ & Liposomes $^{184-186}$ \\
\hline Decompression method $^{(1994,183)}$ & Solv. & Yes & $60 ; 20$ & Liposomes $^{184-186}$ \\
\hline Superfluids Phospholipids Nanosomes $^{(2005,187,188)}$ & Solv. & Yes & 10-60; 6.8-34.5 & Liposomes $^{187,188}$ \\
\hline Supercritical Liposomes Method $^{(1994,189-191)}$ & Solv. & $\begin{array}{l}\text { Yes (low } \\
\text { amount) }\end{array}$ & $60 ; 25$ & Liposomes $^{189-191}$ \\
\hline
\end{tabular}




\begin{tabular}{|c|c|c|c|c|}
\hline Supercritical Reverse Phase Evaporation Method $(2001,181)$ & Solv. & Yes & $60 ; 20$ & Liposomes ${ }^{181,192}$ \\
\hline $\begin{array}{l}\text { Improved Supercritical Reverse Phase Evaporation } \\
\qquad \text { Method }\end{array}$ & Solv. & No & $60 ; 20$ & Liposomes $^{193}$ \\
\hline $\begin{array}{l}\text { Depressurization of an Expanded Liquid Organic Solution- } \\
\qquad \text { SUSPension }{ }^{(2008,194)}\end{array}$ & Co-solv. & Yes & $35 ; 10$ & $\begin{array}{c}\text { Liposomes }{ }^{149,195,196} \\
\text { Quatsomes }{ }^{147,149,194,195}\end{array}$ \\
\hline $\begin{array}{l}\text { Depressurization of an expanded solution into aqueous } \\
\qquad \text { media }(2004,197)\end{array}$ & Co-solv. & Yes & $22 ; 4-5.5$ & Liposomes $^{197,198}$ \\
\hline Rapid Expansion of Supercritical Solutions $(1984,199)$ & Anti-solv. & Yes & $65 ; 30$ & Liposomes $^{199-202}$ \\
\hline Supercritical Anti-Solvent $(1998,182)$ & Anti-solv. & Yes & $30-60 ; 8-33$ & Liposomes $^{182,203-211}$ \\
\hline
\end{tabular}

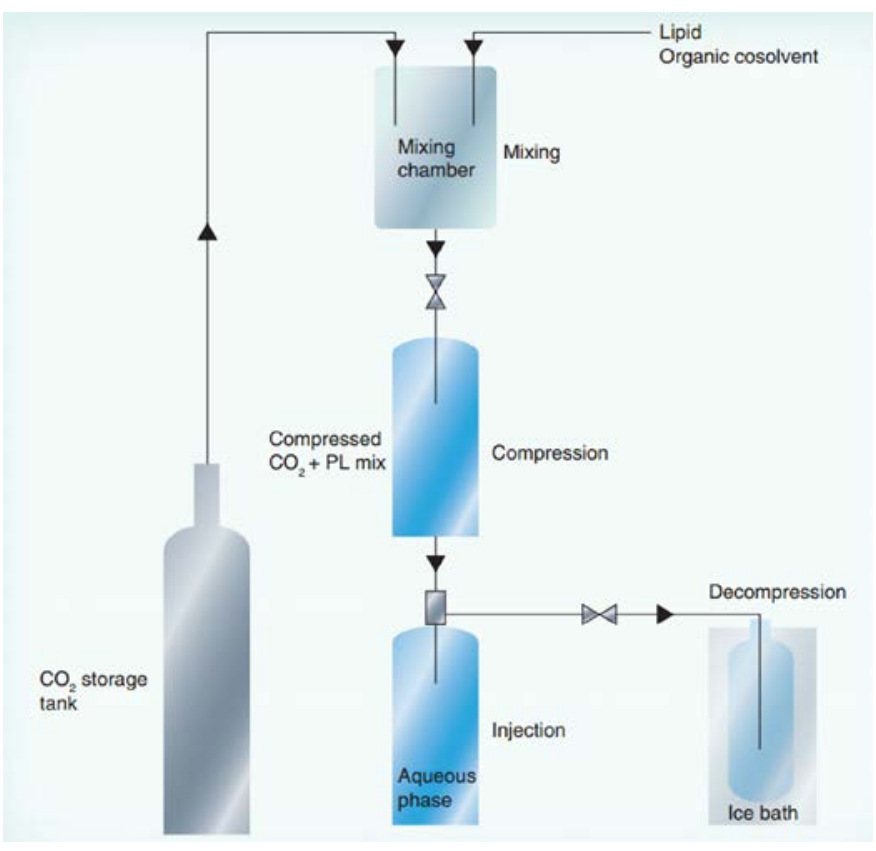

Figure 5. Scheme of the apparatus used in the injection/decompression methods. Reproduced from Ref. 158 with permission from Future Medicine Ltd.

The injection method produced liposomes with superior physical stability and efficiency of drug encapsulation than those of conventional sonication methods ${ }^{186}$. The potential disadvantages of the injection and decompression methods are the use of nozzles, the high capital cost of the equipment, and the high process pressure and temperature requested. Afterwards, a number of variants of the injection/decompression methods have been proposed by the same authors among the years, trying to generate smaller and unilamellar vesicles with a lower polydispersity on one side and to improve the EE on the other side. In the 2005, the SuperFluids Phospholipids Nanosomes (SFS-CFN) were developed $^{187}$.

Small and uniform liposomes (up to $200 \mathrm{~nm}$ ) were produced by

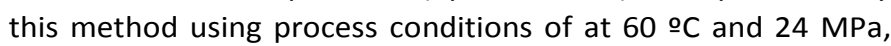
granting a homogeneous dissolution of the materials in the dense gas/co-solvent mixture, using a recirculation loop. In-vivo studies were performed using these liposomes containing paclitaxel and they showed that this formulation had a significantly greater effect on the cancer cells than the conventional therapeutic formulation ${ }^{187}$.

A further implementation of these methods arrived in 2010, when Castor invented an improved process to co-encapsulate hydrophobic and hydrophilic drugs into the nanovesicles. In this method, a phospholipid and hydrophobic drug solution are dissolved in the dense gas with (or without) a co-solvent. Afterwards, the phospholipid and hydrophobic drug solution is depressurized in an aqueous solution containing the hydrophilic drug, resulting in the formation of uniform liposomes that encapsulate hydrophobic and hydrophilic drugs. This method has been proven to be very useful for combination drug therapies ${ }^{188}$. In general, with the injection and decompression methods, as well as their variants, the size and characteristics of nanovesicles depend on the process parameters and material properties, including the size and design of the decompression nozzle, pressure, the rate of decompression, interfacial forces, charge distribution and the nature of the compound being encapsulated. Frederiksen et al. have developed the supercritical liposome method ${ }^{190}$ in the 1994 . This method is similar to the injection method, but in this case the required pressure is higher (up to $25 \mathrm{MPa}$ ) and the amount of co-solvent used is lower (up to 15 -fold less). The yield of the process is around $80 \%$ and most of the liposomes produced are small unilamellar vesicles, having sizes between 20-50 nm. A small fraction of MLVs are also formed. However, their EE was reported to be approximately $20 \%$ lower than that achieved using conventional methods ${ }^{189}$. In the supercritical liposome method phospholipids and Chol are dissolved into supercritical $\mathrm{CO}_{2}$ in the presence of ethanol (5-6\%) and ethanol and $\mathrm{CO}_{2}$ are recirculated many times in order to achieve the complete dissolution of the lipids. Then, the solution is quickly expanded over an aqueous solution containing the hydrophilic drug to be entrapped in. The main difference between this method and the injection method is the fact that here before the expansion, the two phases are in touch inside a capillary. The size of the capillary, i.e. its surface area, strongly influences the size of the liposomes and EE ${ }^{189,191}$. As stated in its name, this method has been developed for liposomes production, but it can be also used for non-liposomal L-NVs. 


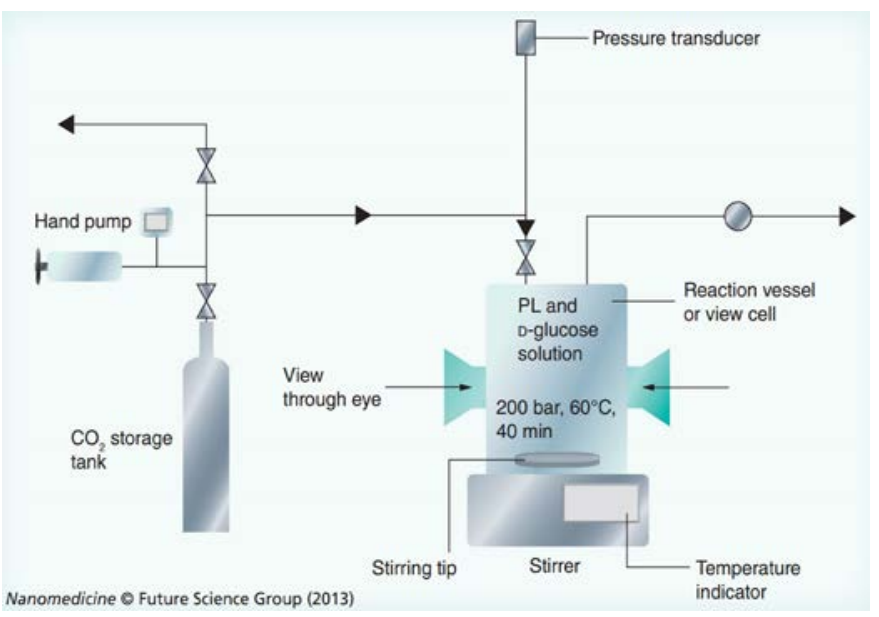

Otake et al. developed the supercritical reverse phase evaporation method (scRPE) in $2001{ }^{181}$ (Figure 6). The basic concept of this method is similar to that of the conventional reverse-phase evaporation method. Thus, lipid, organic co-solvent, and compressed gas are combined in a stirred, variable volume cell at a temperature higher than the phase transition temperature of the phospholipid. An aqueous solution is then slowly introduced into the cell. The system turns to a microemulsion when the amount of water introduced is low (DPPC forms reverse micelles in the water $/ \mathrm{CO}_{2}$ microemulsion), while the microemulsion turns to a macroemulsion as the amount of introduced water increases. The pressure is then released, and vesicles are formed as $\mathrm{CO}_{2}$ evaporates from the aqueous phase upon depressurization. The main difference with respect to the decompression method is the absence here of a sprayer. If compared with the Frederiksen's method, the scRPE method is simpler and requires less CO2.

LUVs $(0.1-1.2 \mu \mathrm{m})$ have been formed with this technology. The mechanism of formation of the vesicles is pretty complicated. Imura et al. studied the mechanism of liposome formation by scRPE. They found that the colloidal structures of the emulsions (water $/ \mathrm{CO}_{2}$ or $\mathrm{CO}_{2} /$ water) obtained before the liposome preparation directly influences the physicochemical properties of the liposomes, such as their particle size, EE and lamellarity ${ }^{212,213}$. Liposomes modified with lipopeptides have been also prepared by the SCRPE method. In particular, bovine serum albumin has been used a model drug in this study in order to verify if this method allow to increase the EE of the protein. The encapsulation was higher (up to 70\%) than those obtained using the conventional Bangham's method, and approximately $90 \%$ of the entrapped drug was retained for up to $48 \mathrm{~h}$ in the produced liposomes, whereas no drug remained in liposomes produced using the Bangham's method after $48 \mathrm{~h}^{192}$. Owing to the single-step nature of this method, scaled-up liposome production is possible. Furthermore, Otake et al. have reported an improved version of scRPE method named as ISCRPE, which does not use any organic solvent. In this case a pure $\mathrm{CO}_{2} /$ water emulsion is formed at 60 o $\mathrm{C}$ and $2 \mathrm{MPa}$. The drug-loading efficiency and stability are improved compared with the SCRPE method. A key parameter of this version is the depressurization rate; the slower is the depressurization, the higher is the control over material properties. The authors also have observed that the EE is increased when longer alkyl chain or unsaturated lipids are used. Furthermore, the shelfstability of such liposomes is longer than that of liposomes produced by Bangham's or Frederiksen's methods. The ISCRPE is very simple compared with the SCRPE method and it is also scalable ${ }^{193}$. In 2008, a CF-based method, called Depressurization of an Expanded Liquid Organic Solution-SUSPension (DELOS-SUSP) for the preparation of colloidal nanomaterials was developed ${ }^{194}$. This method was an intensification of DELOS (Depressurization of an Expanded Liquid Organic Solution) process, with which micron-sized and submicron-sized crystalline particles with high polymorphic purity were prepared ${ }^{214,215}$. DELOS-SUSP method, which involves the depressurization of a $\mathrm{CO}_{2}$-expanded liquid solution of lipids into an aqueous phase, uses a very simple set-up and mild conditions of pressure (10 MPa) and temperature ( $35 \circ \mathrm{O})$ than the above described methodologies. Using this method the straightforward one-step preparation of L-NVs with controlled size distribution, uniform shapes, and good shelf-stability has been achieved ${ }^{195}$. Briefly, the DELOS-SUSP method (Figure 7) consists in loading a solution of the membrane lipid components and the desired hydrophobic bio-actives in an organic solvent (e.g., ethanol) into a high-pressure autoclave, previously driven to the working temperature (Figure 7a). The reactor is then pressurized, with a large amount of compressed $\mathrm{CO}_{2}$ until reach the working pressure (10 MPa) (Figure $7 \mathrm{~b}$ ). Finally in the third stage, the vesicular conjugates are formed by depressurizing the resulting $\mathrm{CO}_{2}$-expanded organic solution over an aqueous phase, which might contain water soluble surfactants and hydrophilic bio-actives (Figure 7c) ${ }^{195}$. In this last step, a flow of $\mathrm{N}_{2}$ at the working pressure is used in order to push down the $\mathrm{CO}_{2}$-expanded solution and to keep constant the pressure inside the reactor. A worthy notorious point is that the depressurization is simply performed by the mean of a valve, without the need of any special nozzle, reducing the complexity of the plant as well as the equipment cost. The $\mathrm{CO}_{2}$ here acts as co-solvent, and its evaporation from the organic expanded solution during the depressurization stage produces a fast, large and homogeneous cooling responsible for the high vesicle-to-vesicle structural homogeneity in comparison to that reached by conventional methods (Figure 8).

DELOS-SUSP technology has shown to be a robust productive process both for the production of liposomes as well as other kinds of L-NVs, in particular quatsomes ${ }^{195,196}$. Many membrane components have been processed by DELOS-SUSP, such as phospholipids, sterols, surfactants. Also, both hydrophobic and hydrophilic bio-actives have been simultaneously loaded in L-NVs by DELOS-SUSP, showing that DELOS-SUSP is a viable platform for the preparation of nanovesicle-bioactive conjugates. For instance, multifunctional conjugates composed by liposomes functionalized with RGD peptides and encapsulating $\alpha$ Galactosidase A (GLA) enzyme were successfully prepared using the DELOS-SUSP ${ }^{195}$. These nanovesicle conjugates showed higher efficacy, in relation to the free proteins, in pre-clinical in vitro and in vivo tests ${ }^{196}$. 


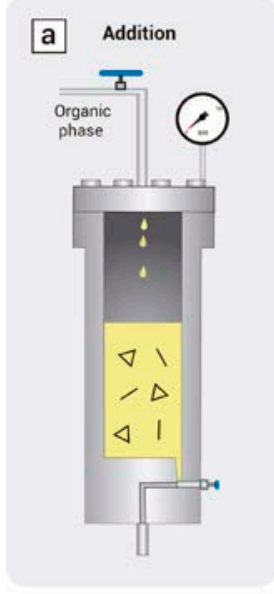

/ Membrane lipids

$\uparrow$ Membrane surfactants

$\triangle$ Hydrophobic actives

[3 Hydrophilic actives
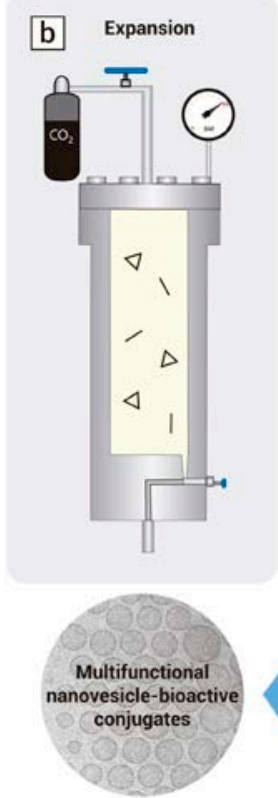
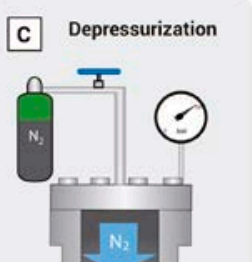

N

$\checkmark$

$\Delta$

$\triangleleft 1$
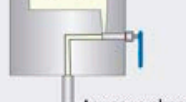

Aqueous phase

古胡=?
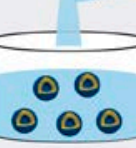

Figure 7. Schematic representation of the DELOS-SUSP method for the efficient preparation of multifunctional nanovesicle-bioactive hybrids. The whole procedure includes the loading (a) of an organic solution of the lipidic membrane components and the desired hydrophobic active compounds/molecules into an autoclave at a working temperature $(T w)$ and atmospheric pressure; the addition of $\mathrm{CO}_{2}(\mathrm{~b})$ to produce a $\mathrm{CO}_{2}$ expanded solution, at a given $X_{C O 2}$, working pressure $(P w)$, and $T w$, where the hydrophobic active and membrane components remain dissolved; and finally, the depressurization (c) of the expanded solution over an aqueous solution, which might contain membrane surfactants and hydrophilic biomolecules, to produce an aqueous dispersion of the nanovesicle-bio-active(s) hybrids. Reprinted with permission from Ref. 195 (I. Cabrera et al., Nano Lett., 2013, 13, 3766-74). Copyright 2013. American Chemical Society.

Furthermore, various kinds of molecules have been successfully integrated in quatsomes by the means of DELOS-SUSP, either by directly processing sterol-like molecules previously modified with a (bio)-active molecule or by loading in the reactor hydrophobic (bio)-active molecules and self-assembling them together with the sterols and the surfactants.

A similar method to DELOS-SUSP, named Depressurization of an expanded solution into aqueous media (DESAM) has been developed by Meure et al. for liposomes production. The lipids are dissolved in an organic solution, that is then expanded by a dense gas. A rapid depressurization occurs at the end of the process over water and the solution was left bubbling for one hour. During this time, also evaporation of the organic solvent was obtained in the vessel, heated and agitated by $\mathrm{CO}_{2}{ }^{197}$.

In this method liposomes form instantaneously after the injection of the expanded liquid in water solution, thanks to lipid spontaneous organization in a bilayer structure that is the favoured configuration and allows to reduce the contact with water of the not-polar lipids chains. Vesicle dimensions can be related to the high turbulence generated during injection and decompression of the expanded liquid. Liposomes with diameters in the range of 50-200 nm have been produced using this technology. However, the major limitation of this technique is the low entrapment efficiency. This process has been designed to use moderate temperatures and pressure. Temelli et al have developed a new CF-based method, based on the modification of ISCRPE and DELOS-SUSP processes for the production of small and unilamellar liposomes. The main advantage of this method is to be free of any organic solvent ${ }^{216}$. CF has been used also as anti-solvent for the preparation of L-NVs. In particular, Rapid Expansion of Supercritical Solutions (RESS) and Supercritical Anti-Solvent (SAS), methods exploit $\mathrm{CO}_{2}$ as anti-solvent; these methods were initially developed for processing a wide variety of difficult-to-comminute solids and then they have been modified for the preparation of L-NVs. Thus, RESS started in 1984, when Krukonis showed its potential for the first time ${ }^{199}$ and since then, several applications have been conducted. In the RESS process, the solute or solutes are solubilized in a dense gas at high pressure ( $>20 \mathrm{MPa}$ ) and this solution is then depressurized through a heated coaxial nozzle into a precipitation chamber at supersonic speed. This rapid expansion $\left(<10^{-5} \mathrm{~s}\right)$ of the solutions inside the chamber leads to a super saturation of the solute and a subsequent precipitation of solute particles with narrow particle size distributions ${ }^{200}$. RESS technology has been used for processing drugs, polymers as well as for L-NVs preparation. Depending on the requirement of the product, various modifications of the process have been developed. In particular, the RESS process has been successful for polymer nanoparticles formation, but it has shown its limits for lipid-based nanoparticles production because lipids are not completely soluble in pure compressed $\mathrm{CO}_{2}$.

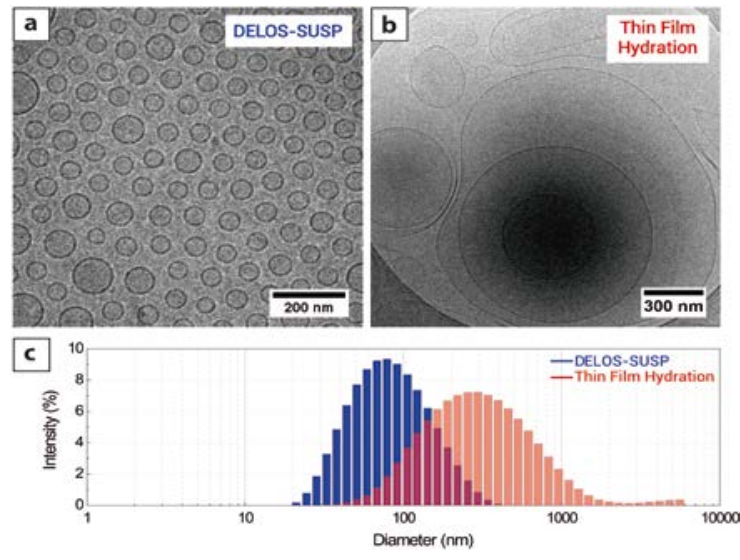

Figure 8. Cryo-TEM micrograph images of quatsomes produced by DELOSSUSP (a) and thin film hydration method (b). Particle size distribution curves measured by dynamic light scattering of disperse systems (c).

Wen et al. introduced some modifications to the conventional RESS process to produce liposomes: PC, Chol, and the essential oil of Atractylodes macrocephala Koidz were dissolved in compressed $\mathrm{CO}_{2}$ and ethanol, and after the system reached the equilibrium, a buffer solution was injected by a syringe pump into the dissolved solutes. The final mixture was then expanded through a nozzle into the collector where liposomes with (i) spherical morphology, (ii) narrow size distribution with an average size of $173 \mathrm{~nm}$, (iii) EE of $82 \%$, and (iv) ethanol amount of $15 \%{ }^{201}$. Zhang et al. also synthesized 
liposomes exploiting the RESS process; using phospholipids and Chol that were dissolved in a sirolimus solution containing water and Tween -80 , and then ethanol was added to the solution. $\mathrm{CO}_{2}$ was then added, obtaining uniform and medium sized with a narrow size distribution nanovesicles ${ }^{202}$. Importantly, this modified RESS process shows good prospects for the scaled-up production of liposomes.

The first example of SAS process is referred to Kikic in $1998{ }^{182}$. A solution composed of the solute and of the organic solvent is sprayed into a continuous phase composed of the supercritical fluid. The latter acts as an anti-solvent for the solute but as a solvent with respect to the organic solvent. The simultaneous dissolution of the supercritical fluid in the liquid droplets and the evaporation of the organic solvent in the supercritical phase induce a super-saturation of the solute into the liquid phase and then to its precipitation. In the SAS process, the final processed material is deprived of any traces of organic solvents. The advantage of SAS over other methods is that rapid contact between the two media (anti-solvent and lipid solution) can be achieved, which speeds up the process of nucleation and growth, resulting in the formation of smaller particles. More recently, Magnan et al. reported that SAS can be used for the production of liposomes using lecithin ${ }^{203}$. Naik et al. developed a method to prepare docetaxel-entrapped PEGylated liposomes using the SAS technique that is suitable for large-scale industrial application. In this method, docetaxel, phospholipids and Chol are first dissolved in organic solvents (chloroform:methanol) and

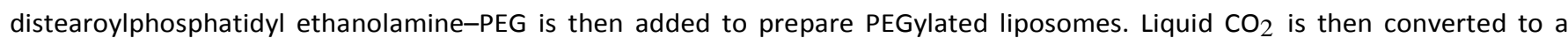
supercritical state, and the mixture is sprayed into a high-pressure vessel in which the pressure and temperature of the vessel are at steady state. The SCF- $\mathrm{CO}_{2}$ in the vessel allows mixing of the drug-lipid solution and precipitation of proliposomes with entrapped docetaxel. Hydration then converts proliposomes into liposomes. The liposomes obtained by this method are small, unilamellar and spherical, with a size range of 200-300 nm and an EE of approximately $80 \%$ was obtained. These formulations were completely free of residual solvents and the liposomes were stable for at least 3 months ${ }^{204}$. Lesoin et al. have compared two methods to produce liposomes encapsulating a fluorescent marker: the SAS method and the Bangham's one. Liposomes were prepared using micronized lecithins and they have been characterized in terms of size and EEs in order to compare the two methods. Liposomes formed from SAS show size distribution mainly bimodal, spreading in the range of $0.1-100 \mu \mathrm{m}$ with $\mathrm{EE}$ between 10 and 20\%. As concerns with the Bangham's method, more dispersed liposomes were formed, EEs obtained were about $20 \%$, and some problems of reproducibility appeared ${ }^{207}$. Lesoin et al. have also introduced a new method called a continuous anti-solvent process in which micronization and hydration are performed in a single step ${ }^{206,207}$ Very recently, RGDgrafted PEGylated docetaxel liposomes were prepared using the SAS technique. Grafting of RGD to the PEGylated docetaxel liposomes significantly improved anti-proliferative activity compared with the free drug and PEGylated docetaxel liposomes. Although these RGD-grafted PEGylated docetaxel liposomes are still at an early preclinical stage, they may be a feasible treatment option for breast cancer treatment if future studies demonstrate that they have low toxicity, good bioavailability and high efficacy ${ }^{205}$. In 2011, Hwang et al. introduced a novel SCF- $\mathrm{CO}_{2}$ method based on the SAS technique to prepare liposomes in which a dried mixture of lipids, Chol and the drug of interest (Amphotericin B (AmB)) are coated with anhydrous lactose, a watersoluble carrier. They compared these liposomes to the ones produced by conventional techniques. Liposomes obtained after homogenization were unilamellar and spherical in shape with an average diameter of $100 \mathrm{~nm}$ with an EE greater than $80 \%$. SCF$\mathrm{CO}_{2}$ liposomes were found to be more stable than conventional liposomes for a test period of 1 month, leading the authors to propose the possibility of long-term storage of $\mathrm{SCF}-\mathrm{CO}_{2}$ liposomes by lyophilization. A hemolysis study revealed that liposomal AmB prepared by the SCF- $\mathrm{CO}_{2}$ method was less hematotoxic than a commercial micellar formulation of AmB Fungizone ${ }^{\circledR}$ (Bristol-Myers Squibb, NJ, USA). This method could, therefore, be a superior alternative to the conventional Bangham's method, and is well suited to the mass production of liposomes ${ }^{208}$. Xia et al. investigated process parameters for the efficient preparation of liposomes encapsulating coenzyme Q10 using the SAS technique ${ }^{209}$. Karn et al. ${ }^{210}$ adopted the method invented by Hwang et al. ${ }^{208}$ to prepare liposomal cyclosporine A (CSA). The differences between liposomes prepared using the SCF-CO 2 and conventional modified Bangham's methods were thoroughly investigated, revealing that liposomes prepared using $\mathrm{SCF}^{-\mathrm{CO}_{2}}$ were physically and chemically more stable than liposomes prepared using the conventional method ${ }^{206-208}$. The SCF-CO 2 liposomes were smaller, uniform and more spherical than the liposomes prepared using the conventional method. Additionally, a nontoxic organic solvent (ethanol) was used, which evaporated completely before hydration.

\section{Other Non-conventional Preparation Methods}

Over the last years, microfluidic technologies have been mainly developed and used as tools in chemical synthesis and biological analysis. Nevertheless, it has received an increasing interest as a novel platform for the preparation of nano- and microparticles ${ }^{217}$. It is a versatile technology that enables a precise control and manipulation of fluids and liquid flows in channels at the micrometer scale, allowing the implementation of the mixing process into small planar chips and devices. Due to its characteristics, it can provide a rapid and tunable mixing with homogenous reaction environments, and a high-throughput experimental platform ${ }^{217,218}$. Because of the exquisite control of flow and mixing conditions, it has been applied for producing $L-$ NVs, altering particle size and improving homogeneity of particle size distributions as well ${ }^{219-221}$. The application of microfluidics to the synthesis of nanovesicles in novel lab-on-a-chip based devices can dramatically reduce the time required for sample preparation as well as the costs associated with experimental work ${ }^{218}$. 


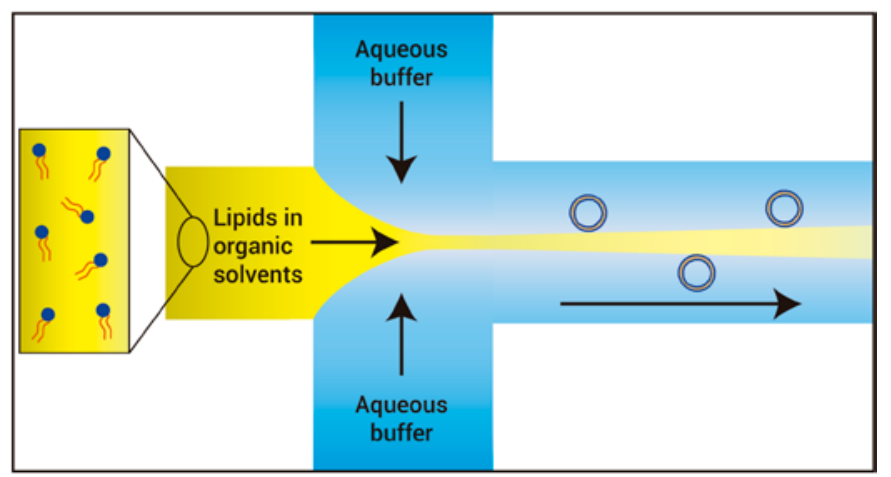

Figure 9. Microfluidics technology to produce liposomes with high precision and efficiency. Cross-flow where the aqueous buffer is introduced in a different axis to the lipids in organic solvents.

Jahn et al. (2004 and 2007) developed a microfluidic hydrodynamic focusing (MHF) method for controlled liposome formation. A stream of aqueous solution is injected in a small channel (up to $500 \mu \mathrm{m}$ ), resulting in a laminar flow. A perpendicular flow of lipids dissolved in an organic phase is injected in the channels, mixing with the aqueous phase. The organic phase is diluted and the lipids self-assembled into vesicles (see Figure 9). The size, morphology and lamellarity of the vesicles are strongly affected by the process parameters as the size of the microchannels, the concentration of the lipids, the ratio between the two flows, and the magnitude of flows ${ }^{222,223}$. The NanoAssembler platform and the NanoAssembler Scale-up platform developed by Precison Nanosystems, INC., Canada, have produced liposomes both at the lab-scale and at clinical-scale using the microfluidic technology ${ }^{218}$. In fact, microfluidization can be scaled up by increasing the number of channels in a parallel configuration. Nevertheless, it can be problematic for the processing of thermo-labile compounds due to the high shears developed in this process. Also, some processing problems, such as channel blocking, might take place making difficult to translate to industry. Another aspect to take into account for this kind of sophisticated equipment is the required cleaning step after each batch production. A GMP-compliant procedure should include cleaning and cleaning validation procedures to avoid batch-to-batch or product-to-product contamination. Up to now there is not clear whether at industrial scale it would be possible to ensure the cleanliness of multiple nanometer-sized channels. Apart from the techniques based on microfluidics and CF technology that present promise features, other types of non-conventional methods for preparing nanovesicles have been developed and proposed in the last years. Some of these techniques are based on the use of sophisticated templates over which the vesicles are formed, aiming to achieve size-controlled and monodispersed colloidal dispersions ${ }^{224-227}$. For example, DNA/protamine polyplexes were used as templates for the production of vesicles smaller than $200 \mathrm{~nm}$ using the layer-by-layer method intended for gene delivery ${ }^{225}$. In another study, DNA nano-octahedron obtained through DNA engineering and inspired in the shape of virus, were used as templates for the preparation of lipid-based vesicles with $76 \mathrm{~nm}$ on diameter ${ }^{227}$. Yang et al, produced monodisperse SUVs of different sizes and compositions using the DNA origami technique. The DNA-origami rings/nanotemplates served as an exoskeleton inside which the SUVs are formed, contrary to the majority of other techniques using templates as endoskeleton. Nanotemplates of 29, 46, 60, and $94 \mathrm{~nm}$ originated liposomes of $\sim 22,45,58$ and $94 \mathrm{~nm}$, presenting a high monodisperse distribution with at least $85 \%$ of the particles falling within the expected size range, and a small percentage of particles with smaller sizes ${ }^{224}$. Despite the promising results, the scalability of these techniques for drug delivery purposes could be impaired by the high costs of DNA nanotemplates' production. Other method that has showed to produce nanovesicles is based on the freeze-drying of emulsions ${ }^{228-230}$. The method is based on the dissolution of hydrophilic components of the formulation (like drugs and cryoprotectans) in the water phase, while the hydrophobic components (like drugs and lipids) are dissolved in an organic solvent. After emulsification, the formulation is freeze-dryed to eliminate the liquid phase and the vesicles form by suspending the obtained dry powder in an aqueous solution (Figure 10). For example, PC:PS:Chol unilamelar liposomes smaller than $200 \mathrm{~nm}$ and able to encapsulate hydrophobic (flurbiprofen), hydrophilic (paeoniflorin), and amphiphilic (berberin) drugs were efficiently prepared by this method ${ }^{228}$. Another interesting method for preparing nanovesicles was reported by $\mathrm{Yu}$ et al. and consists of the production of nanofibers composed by phospholipids and a hydrophilic polymer (filament-forming matrix) by electrospinning first, serving as liposomes precursors ${ }^{231}$.

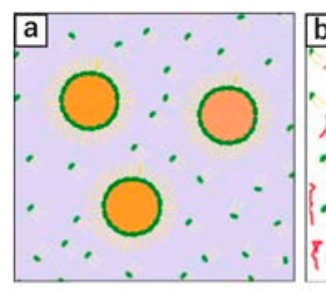

Wo emulsions Freeze-drying

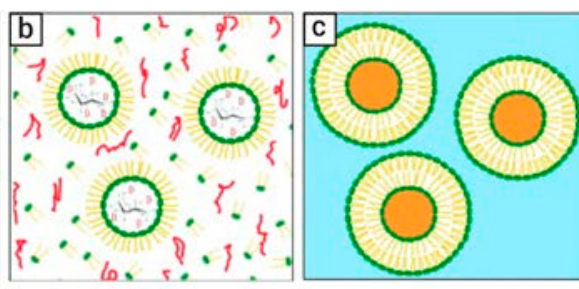

Rehydration

Figure 10. Schematic representation of the freeze-drying of emulsions method. Reprinted from Ref. 228, Chem. Phys. Lipids, 2011, 164, 151157. T. Wang, N. Wang, T. Wang, W. Sun and T. Li., "Preparation of submicron liposomes exhibiting efficient entrapment of drugs by freeze-drying water-in-oil emulsions", Copyright 2016, with permission from Elsevier.

When in contact to an aqueous solution the hydrophilic polymer disperses into the solution, releasing the phospholipids that self-assemble into vesicles. Through this technique was possible to produce nanovesicles of PC smaller than $200 \mathrm{~nm}$ from PC: polyvinylpyrrolidone (PVP) nanofibers. In this case, the size of the liposomes can be controlled by changing the ratio of PC:PVP used to produce nanofibers. This method presents some advantages over conventional methods since is free of heating, cooling, agitation, or postformation steps ${ }^{231}$, but it also has some drawbacks mainly related to its scalability.

\section{Biomedical applications of nanovesicles}




\section{Nanovesicles for delivery of pharmaceuticals}

Many therapeutics have been benefiting with the development of Nanomedicine, and among them, anticancer drugs are the most studied ones and presenting the highest number of approved or under clinical evaluation nano-based drug products ${ }^{232}$. The important progresses observed in the cancer treatment have resulted, in the last two decades, in an improvement of the clinical outcomes and a decrease of the mortality rates ${ }^{233}$. Different nanovesicles have been proposed as vehicles of anticancer agents including paclitaxel ${ }^{234,68}$, doxorubicin ${ }^{235,236}$, vinorelbine ${ }^{237}$, cisplatin ${ }^{238}$, 5-fluorouracil ${ }^{112}$, lapatinib ${ }^{239}$, among others, with some formulations marketed and used in clinical practice (Table 4) or even enrolling clinical evaluation (Table 5). As previously mentioned in this Review, among the different nano-based products available, liposomes have been the systems more studied, being the first nanomedicines reaching the market (Doxil/Caelyx ${ }^{\circ}$ ). As referred, Doxil/Caelyx was the first nanomedicine-based system reaching the market in 1995, and its success boosted the development of new nanotechnologybased DDS. This stealth liposomes (around $100 \mathrm{~nm}$ ) composed of MPEG-DSPE, HSPC and Chol encapsulating doxorubicin were able to alter the biodistribution of the drug and increase its half-life, increasing therefore its therapeutic efficacy (passively targeting the tumors) and reducing its well-known side effects, namely cardiotoxicity and neutropenia ${ }^{240,241}$. One of the most interesting characteristics of Doxil/Caelyx is related to its smart drug loading mechanism based in the use of transmembrane ammonium sulfate gradients to actively load amphipathic weak bases like doxorubicin after liposomes production. This method not only allows the entrapment of high amounts of the drug in the small aqueous core of liposomes without requiring preparation of their in acidic $\mathrm{pH}$ nor alkalization of the extra-liposomal aqueous phase, but also presents a strong loading stability of the drug both in storage and blood circulation ${ }^{241,242}$.

Together with liposomes, other vesicular systems, especially non-liposomal L-NVs, have been developed and proposed as promising and alternative DDS in the last years. Table 4 and 5 report some examples of nanovesicles-based drug products already on the market or under clinical evaluation. Liposomes and niosomes have shown to improve the oral bioavailability of paclitaxel, a Biopharmaceutical Classification System (BCS) class IV drug whose oral delivery is highly impaired by its physicochemical characteristics ${ }^{243,244}$. Liposomes coated with poly(acrylic acid) and poly(allylamine hydrochloride) were also able to improve the oral bioavailability of doxorubicin, and present an in vivo antitumor activity after a multiple oral dose regimen comparable to a single intra venous administration of the commercial formulation Lipo-Dox ${ }^{245}$. In another study, the surface modification of liposomes encapsulating doxorubicin with anti-HER2/neu peptide (AHNP) improved the in vivo therapeutic index and anticancer activity of the drug against breast cancer when compared with non-targeted liposomes such as Caelyx (Figure 11) ${ }^{236}$. The encapsulation of mitoxantrone into ethosomes improved its anticancer activity against melanoma tumors by a reduction in the tumor size and an induction of an in vivo anticancer immune response ${ }^{246}$. In another study, 5fluorouracil intended for dermal application was encapsulated into liposomes, transfersomes and niosomes. All the vesicular systems promoted an improvement of the biopharmaceutical characteristics of the drug, being transfersomes the vehicle that presented the best anticancer activity due to higher penetration capacity ${ }^{247}$. The topical administration of anticancer drugs could be an effective and safer way to treat skin cancer over conventional therapies since they reduce the systemic side effects and an increase of the therapeutic index of drugs.

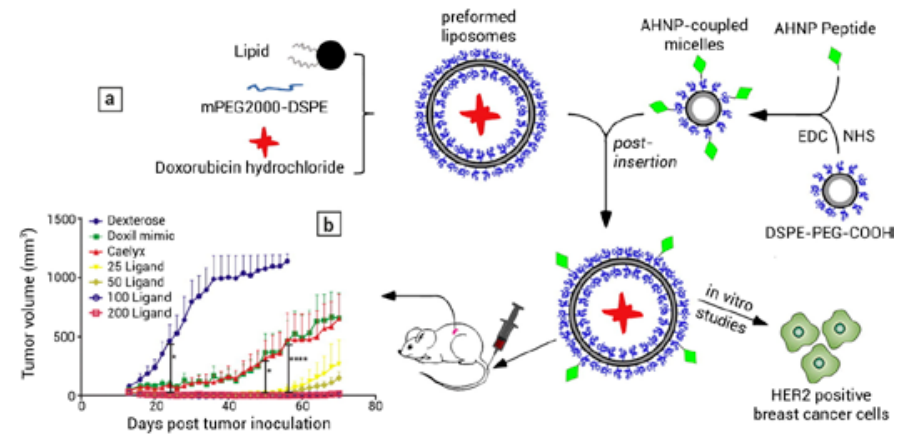

Figure 11. Preparation (a) and efficacy assessment (b) of AHNP modified liposomes encapsulating doxorubicin. In the in vivo studies the mean relative change in tumor volume in bearing mice treated with a dose of $15 \mathrm{mg} / \mathrm{kg}$ DOX formulations or dextrose $5 \%$ as i.v. injection on day 13 after tumor inoculation was assessed over time. Reprinted from Ref. 236, Eur J Pharm Sci, 2016, 86, 125-135. M. Zahmatkeshan, F. Gheybi, S. Mahdi Rezayat, M. Reza Jaafari "Improved drug delivery and therapeutic efficacy of PEgylated liposomal doxorubicin by targeting antiHER2 peptide in murine breast tumor model", Copyright 2016, with permission from Elsevier.

Resistant infectious diseases, especially the nosocomial respiratory infections, impose a challenge to the current available clinical therapeutic regimens. In this context, DDS based on nanotechnology, including nanovesicles, arise as promising alternatives to improve the therapeutic index and clinical relevance of anti-infectious drugs. Many research groups have been developing liposomes for encapsulation of anti-infectious drugs like tobramycin ${ }^{248,249}$, polymyxin $\mathrm{B}^{250}$, amphotericin B ${ }^{251}$, or ciprofloxacin ${ }^{252-256}$. For example, administration of ciprofloxacin-loaded liposomes resulted in at least $86 \%$ survival of animals suffering from lethal tularemia 14 days post-administration ${ }^{253}$, while liposomal tobramycin was therapeutically more effective than the conventional formulation (Tobi , PathoGenesis Canada) against Pseudomonas aeruginosa and Burkholderia cepacia in a multiple dose treatment conducted in infected rats ${ }^{248,249}$. Some of the most severe infectious diseases like Tuberculosis, HIV or Legionella are induced by intracellular pathogens that infect internally the cells, evading from the mononuclear phagocyte system and turning them as reservoirs ${ }^{257}$.

The intracellular localization of the pathogens becomes an obstacle to an effective and prompt treatment due to the difficulties of drugs present in conventional formulations to reach the therapeutic targets ${ }^{257}$. For presenting a higher cellular uptake, nano- 
DDS have been proposed as improved systems to delivery drugs at effective doses to the cytosol of cells. For example, the administration of streptomycin ${ }^{258,259}$, kanamycin ${ }^{260}$, amikacin ${ }^{261,262}$, and gentamicin ${ }^{263}$ encapsulated into liposomes increased their in vivo efficacy by reducing the viable bacteria counts of pathogens such as Mycobacterium tuberculosis and Klebsiella pneumoniae. Regarding macrophages targeting, the encapsulation of rifampicin into PC:Chol:dicetylphosphate liposomes imposed a significant reduction of the Mycobacterium smegmatis viability inside macrophages compared to the free drug. The modification of the liposome surfaces with antigens such as maleylated bovine serum albumin (MBSA) and O-steroyl amylopectin (O-SAP) to actively targeting macrophages further improve the therapeutic efficacy of the systems ${ }^{264}$. In other studies, mannosylated liposomes improved the uptake of ciprofloxacin by alveolar macrophages ${ }^{254}$, while O-palmitoyl mannan (OPM) and O-polmitoyl pullulan (OPP) were used as ligands to target amphotericin B-loaded PC:Chol liposomes to alveolar macrophages ${ }^{251}$.

Referring to the non-liposomal L-NVs, transfersomes due to their ultraflexibility and ethosomes due to their content in ethanol offer the better features for improved skin drug delivery ${ }^{117,265-267}$. Transfersomes have been proposed as delivery systems of drugs with different applications, such as meloxicam ${ }^{268}$ and diclofenac ${ }^{269}$ for the treatment of rheumatoid arthritis, raloxifene for the treatment of breast cancer ${ }^{270}$, sertraline for the treatment of depression ${ }^{42}$, amphotericin B for the treatment of Leishmaniasis ${ }^{271}$, ketoconazole for the treatment of fungal infections ${ }^{272}$ or felodipine for the treatment of hypertension ${ }^{273}$. For example, transfersomes composed by Span 80, soya lecithin, and Carbopol 940 were proposed for transdermal delivery of sertraline as alternative to its oral administration in order to avoid the hepatic first-pass metabolism and reduce the required doses. The transfersomes improved both ex vivo and in vivo permeation and therapeutic activity of sertraline compared to the drug in solution or gel ${ }^{42}$. In another study, transfersomes have also shown to improve the skin permeation and the efficacy of amphotericin B against $L$. donovani when compared to a conventional liposomal formulation, being a promising alternative to the treatment of visceral Leishmaniasis ${ }^{271}$. Regarding ethosomes, Ahmed, et al. (2016) developed ethosomes composed by PC, Chol, ethanol and propylene glycol, encapsulating the anti-diabetic drug glimepiride, intended for transdermal systemic delivery when incorporated into a transdermal patch ${ }^{274}$. As previously mentioned, ethosomes promoted higher skin permeation and also show a superior bioavailabity of the drug in human volunteers, compared to the free drug in the patch, becoming a promising alternative to the oral delivery of glimepiride ${ }^{274}$. Other studies propose ethosomes as dermal and nasal delivery systems of drugs like aceclofenac ${ }^{69}$, zolmitriptan ${ }^{275}$, piroxicam ${ }^{276}$, lidocaine ${ }^{277}$, celecoxib ${ }^{278}$ or methoxsalen ${ }^{92}$. Niosomes have been proposed as vehicles for delivery of a variety of drugs via different administration routes, arising as promising carriers for ocular delivery ${ }^{77,279}$. Tracrolimus-loaded niosomes have shown to be biocompatible with the cornea, delaying the occurrence of corneal allograft rejection in transplanted animals to a higher extent than free drug and the typical CsA treatment ${ }^{280}$. Other drugs like fluconazole ${ }^{281}$, naltrexone ${ }^{282}$, gentamicin ${ }^{283}$, or prednisolone ${ }^{284}$ have also been encapsulated into niosomes presenting interesting results.

Table 4. Examples of vesicular formulations with marketed authorization. CM - Conventional method; NCM - Non-conventional method.

\begin{tabular}{|c|c|c|c|c|c|}
\hline $\begin{array}{l}\text { Preparation } \\
\text { Method }\end{array}$ & Type of vesicle & Drug & Disease & Trade name & Manufacturer \\
\hline $\mathrm{CM}$ & Liposomes & Amphotericin B & Severe fungal infections & AmBisome & Gilead Sciences, Inc. \\
\hline CM & Liposomes & Daunorubicin & $\begin{array}{l}\text { Advanced HIV-related } \\
\text { Kaposi's sarcoma }\end{array}$ & DaunoXome & Galen Limited \\
\hline CM & Liposomes & Doxorubicin & $\begin{array}{l}\text { Metastatic breast } \\
\text { cancer }\end{array}$ & Myocet & $\begin{array}{l}\text { Teva Pharmaceutical } \\
\text { Industries Ltd. }\end{array}$ \\
\hline CM & Liposomes & Doxorubicin & $\begin{array}{l}\text { Ovarian cancer and } \\
\text { HIV-related Kaposi's } \\
\text { sarcoma }\end{array}$ & Doxil/Caelyx & Janssen Products \\
\hline CM & Sphingosomes & Vincristine & $\begin{array}{c}\text { Acute lymphoblastic } \\
\text { leukemia }\end{array}$ & Marqibo & $\begin{array}{l}\text { Spectrum Pharmaceuticals, } \\
\text { Inc. }\end{array}$ \\
\hline CM & Liposomes & Mifamurtide & Osteosarcoma & Mepact & $\begin{array}{l}\text { Takeda Pharmaceutical } \\
\text { Company Limited }\end{array}$ \\
\hline CM & Liposomes & Doxorubicin & $\begin{array}{c}\text { Kaposi's sarcoma, } \\
\text { breast and ovarian } \\
\text { cancer }\end{array}$ & Lipo-Dox & Taiwan Liposome \\
\hline
\end{tabular}




\begin{tabular}{|c|c|c|c|c|c|}
\hline $\mathrm{CM}$ & Liposomes & Verteporfin & $\begin{array}{c}\text { Age-related macular } \\
\text { degeneration, ocular } \\
\text { histoplasmosis }\end{array}$ & Visudyne & Novartis AG \\
\hline $\mathrm{CM}$ & Liposomes & Irinotecan & $\begin{array}{c}\text { Metastatic } \\
\text { adenocarcinoma of the } \\
\text { pancreas }\end{array}$ & Onivyde & $\begin{array}{c}\text { Merrimack } \\
\text { Pharmaceuticals, Inc. }\end{array}$ \\
\hline CM & Liposomes & Paclitaxel & Advancer solid tumours & Lipusu & Luye Pharma Group \\
\hline $\mathrm{CM}$ & $\begin{array}{l}\text { Virosomes } \\
\text { (vaccine) }\end{array}$ & $\begin{array}{l}\text { Inactivated } \\
\text { hepatitis A } \\
\text { antigen }\end{array}$ & Hepatitis A & Epaxal & Crucell \\
\hline $\mathrm{CM}$ & $\begin{array}{l}\text { Virosomes } \\
\text { (vaccine) }\end{array}$ & $\begin{array}{l}\text { Inactive } \\
\text { hemagglutinin } \\
\text { of influenza } \\
\text { virus strains A } \\
\text { and B }\end{array}$ & Influenza & Inflexal V & Crucell \\
\hline NCM & Liposomes & Cisplatin & Pancreatic cancer & Lipoplatin & Regulon Inc \\
\hline
\end{tabular}

\section{Nanovesicles for delivery of biopharmaceuticals}

L-NVs have shown to be good carrier candidates for the delivery of biopharmaceuticals as well. As for pharmaceuticals, liposomes are the most studied and proposed lipid-based nanovesicles and have shown up to now the most promising results both in vitro and in vivo. However, as referred before, they also present some limitations, such as a low therapeutic efficacy, a poor long-term stability and a low transfection efficiency in the case of nucleic acid delivery ${ }^{25,31,66}$. Fewer examples of liposomal formulations for delivering biopharmaceuticals are nowadays under clinical evaluation, and these are still in the early stage. This low number of products enrolling clinical trials is related with the poor stability of biopharmaceuticals during its formulation, and challenges observed in the pilot to industrial scale-up of the methods of preparation used for these novel products. Liposomal formulations in clinical trials display a large variety of loaded biopharmaceutical drugs, such as insulin, Grb2 antisense oligonucleotide, siRNA against PKN3, p53 plasmid DNA, RSV SHe Antigen, among others (Table 4). Liposomes have shown to improve pharmacological properties of peptides and proteins, and several enzymes have been proposed for liposomal delivery such as glucose oxidase, glucose- 6 -phosphate dehydrogenase, hexokinase, $\beta$-galactosidase, $\beta$-glucuronidase, glucocerebrosidase, $\alpha$-mannosidase or amiloglucosidase ${ }^{285}$. For example, liposomes have been used to improve both the bioavailability and absorption of proteins in the harsh environment of the intestinal tract (strong acidic medium and presence of enzymes) ${ }^{286}$. In another study, after administration of liposomes containing $\beta$-fructofuranosidase in rats, it was observed that within an hour, $50 \%$ of the administered enzyme remain in the circulation, and the activity of the enzyme was preserved at least after 2 days in the liver ${ }^{287}$. After oral administration of insulin and sodium taurocholate loaded on a liposome system it was observed a markedly reduction on the blood glucose levels both in vitro and in vivo ${ }^{288}$. However, another study in patients using insulin loaded into liposomes for the treatment of Type-2 diabetes mellitus, showed that insulin did not delay or prevent type 1 diabetes ${ }^{289}$. Moreover, several absorption enhancers, such as fatty acids, surfactants and bile salts, have been used in animal models for the oral delivery of biomacromolecules ${ }^{290}$. Furthermore, it has been demonstrated the ability of liposomes to enter into the cytoplasm and lysosomes of live cells, which open new opportunities for the treatment of inherited diseases caused by the abnormal function of the enzymes. For example, liposome containing $\beta$-galaclosidase were able to degrade glycopeptides (GM1-ganglioside) accumulated in lysosomes of feline fibroblasts, which have deficient $\beta$-galactosidase activity ${ }^{291}$. Many studies also have been performed using transfersomes for protein and peptide delivery. For example, buccal delivery of insulin was achieved when transfersomes were used, showing an intercellular transdermal transfer rates of the order of 50\%; however recent studies have been unable to reproduce these initial results ${ }^{292}$. Morrow and co-workers found a reduction in the glucose levels of both in mice and humans, after transcutaneous administration of insulin loaded into transfersomes ${ }^{293}$. Transfersomes have been shown promising results for delivery of calcitonin, $\alpha$ - and $\gamma$-interferon, $\mathrm{Cu}$ - $\mathrm{Zn}$ superoxide dismutase, and serum albumin across the skin ${ }^{294}$. Moreover, transfersomes have been able to deliver genetic material into the cells ${ }^{295}$. For example, cationic transfersomes have been used as carriers for topical administration of plasmid DNA encoding hepatitis B surface antigen (HBsAg). After topical administration of these HBsAg-loaded cationic transfersomes it was observed a significantly higher antiHBsAg antibody titer and cytokines levels compared with naked DNA ${ }^{71}$.

Up to now, there are only two clinically approved L-NVs for biopharmaceutical delivery, Epaxal and Inflexal $\mathrm{V}^{\circ}$, which are liposome-based vaccine products, classified as virosomes. Epaxal is a hepatitis A virus vaccine which is based on an inactivated 
hepatitis $A$ antigen anchored into the virosomes. Inflexal $V^{\oplus}$ is an influenza virus vaccine which is based on inactive hemagglutinin of influenza virus strains $A$ and $B$ anchored into virosomes. Both vaccines are approved for intramuscular administration, are well-tolerated, safe, and show effective and durable immunization against the viruses by strong stimulation of the immune system

Table 5. Examples of vesicles for delivery of pharmaceuticals and biopharmaceuticals under clinical evaluation. CP - Clinical trial phase; CM Conventional method; NCM - Non-conventional method.

\begin{tabular}{|c|c|c|c|c|c|c|}
\hline $\begin{array}{l}\text { Preparation } \\
\text { Method }\end{array}$ & $\begin{array}{l}\text { Type of } \\
\text { vesicle }\end{array}$ & Drug & Disease & Name & $\mathbf{C P}$ & Ref. \\
\hline CM & Liposomes & $\begin{array}{l}\text { 24-mer oligonucleotide targeting } \\
\text { BCL-2 }\end{array}$ & $\begin{array}{l}\text { Non-Hodgkin's Lymphoma and } \\
\text { Richter's Transformation }\end{array}$ & PNT2258 & 2 & 296,297 \\
\hline CM & Liposomes & Amikacin & Cystic Fibrosis, Bronchiectasis & Arikace & 3 & 298 \\
\hline CM & Liposomes & Belotecan & Advanced Malignancies & S-CKD602 & 1 & 299 \\
\hline CM & Liposomes & Cisplatin & $\begin{array}{c}\text { Advanced or refractory solid } \\
\text { tumours }\end{array}$ & LiPlaCis & 1 & 300 \\
\hline CM & Liposomes & Cisplatin & Ovarian Cancer & SPI-077 & 2 & 301 \\
\hline CM & Liposomes & Cisplatin analog & Advanced solid tumours & Aroplatin & 2 & 302 \\
\hline CM & Liposomes & $\begin{array}{l}\text { C-RAF Antisense } \\
\text { Oligodeoxynucleotide } 2\end{array}$ & Advanced Solid Tumors & LErafAON & 1 & 303 \\
\hline CM & Liposomes & Curcumin & Cancer & Lipocurc & 2 & 304 \\
\hline CM & Liposomes & Cytarabine:daunorubicin & $\begin{array}{l}\text { Myelodysplastic syndrome and } \\
\text { acute myeloid leukemia }\end{array}$ & Vyxeos & 3 & 305,306 \\
\hline CM & Liposomes & Docetaxel & $\begin{array}{l}\text { Advanced or Metastatic } \\
\text { Pancreatic Cancer }\end{array}$ & LE-DT & 2 & 307 \\
\hline CM & Liposomes & Doxorubicin & $\begin{array}{l}\text { Liver, breast and pancreatic } \\
\text { cancer }\end{array}$ & ThermoDox & 3 & 308,309 \\
\hline CM & Liposomes & Doxorubicin & $\begin{array}{l}\text { Brain metastases of breast } \\
\text { cancer }\end{array}$ & 2B3-101 & 2 & 310 \\
\hline CM & Liposomes & Doxorubicin & $\begin{array}{c}\text { Advanced/Metastatic Breast } \\
\text { Cancer Patients }\end{array}$ & MM-302 & 3 & 311 \\
\hline CM & $\begin{array}{l}\text { Liposomes } \\
\text { (vaccine) }\end{array}$ & $\begin{array}{l}\text { HLA-A2-restricted peptides, T } \\
\text { Helper Peptide, polynucleotide } \\
\text { adjuvant }\end{array}$ & $\begin{array}{c}\text { Advanced Stage Ovarian, Breast } \\
\text { and Prostate Cancer }\end{array}$ & DPX-0907 & 1 & 312 \\
\hline CM & Liposomes & Insulin & Type-2 diabetes mellitus & HDV-I & 3 & 313 \\
\hline CM & Liposomes & Irinotecan:Floxuridine & Advanced Colorectal Cancer & CPX-1 & 2 & 314 \\
\hline CM & Liposomes & Lurtotecan & Solid tumours & OSI-211 & 2 & 315,316 \\
\hline CM & Liposomes & MicroRNA RX34 & $\begin{array}{c}\text { Solid tumors and hematologic } \\
\text { malignancies }\end{array}$ & MRX34 & 1 & 317 \\
\hline
\end{tabular}




\begin{tabular}{|c|c|c|c|c|c|c|}
\hline $\mathrm{CM}$ & Liposomes & Mitomycin-C Lipid-based Prodrug & Solid Tumors & Promitil & 1 & 318 \\
\hline $\mathrm{CM}$ & Liposomes & Mitoxantrone & Solid tumours & LEM-ETU & 1 & 319 \\
\hline $\mathrm{CM}$ & Liposomes & p53 & $\begin{array}{c}\text { Glioblastoma, Metastatic } \\
\text { Pancreatic Cancer }\end{array}$ & SGT-53 & 2 & 320,321 \\
\hline $\mathrm{CM}$ & Liposomes & Paclitaxel & Advanced breast cancer & LEP-ETU & 2 & 322 \\
\hline $\mathrm{CM}$ & Liposomes & Paclitaxel & $\begin{array}{c}\text { Breast, pancreas and liver } \\
\text { tumours }\end{array}$ & EndoTag-1 & 2 & 323,324 \\
\hline $\mathrm{CM}$ & Liposomes & Prednisolone & $\begin{array}{l}\text { Hemodialysis fistula maturation } \\
\text { and Rheumatoid arthritis }\end{array}$ & Nanocort & 3 & 325,326 \\
\hline CM & Liposomes & RB94 plasmid DNA & Solid tumours & SGT-94 & 1 & 327 \\
\hline $\mathrm{CM}$ & $\begin{array}{l}\text { Liposomes } \\
\text { (vaccine) }\end{array}$ & RSV SHe Antigen & $\begin{array}{l}\text { Respiratory Syncytial } \\
\text { Virus infection }\end{array}$ & DPX-RSV & 1 & 328 \\
\hline $\mathrm{CM}$ & Liposomes & siRNA against PKN3 & $\begin{array}{c}\text { Advanced Solid tumours and } \\
\text { pancreatic cancer }\end{array}$ & Atu027 & 2 & 329,330 \\
\hline $\mathrm{CM}$ & Liposomes & SN38 & Colorectal Cancer & LE-SN38 & 2 & 331 \\
\hline $\mathrm{CM}$ & $\begin{array}{l}\text { Liposomes } \\
\text { (vaccine) }\end{array}$ & Survivin & $\begin{array}{c}\text { Advanced Stage Ovarian, } \\
\text { Fallopian or Peritoneal Cancer }\end{array}$ & $\begin{array}{l}\text { DPX- } \\
\text { Survivac }\end{array}$ & 2 & 332 \\
\hline $\mathrm{CM}$ & $\begin{array}{l}\text { Liposomes } \\
\text { (vaccine) }\end{array}$ & Tecemotide & $\begin{array}{l}\text { Non-Small Cell Lung Cancer, } \\
\text { solid tumours }\end{array}$ & Stimuvax & 3 & $\begin{array}{c}333- \\
335\end{array}$ \\
\hline $\mathrm{CM}$ & Liposomes & Thymidylate synthase inhibitor & Advanced Solid Tumors & OSI-7904L & 2 & 336,337 \\
\hline CM & Sphingosomes & Topotecan & Advanced solid tumours & Brakiva & 1 & 338,339 \\
\hline $\mathrm{CM}$ & Sphingosomes & Vinorelbine & $\begin{array}{c}\text { Advanced solid tumors, non- } \\
\text { Hodgkin's and Hodgkin's } \\
\text { lymphoma }\end{array}$ & Alocrest & 1 & 340 \\
\hline $\mathrm{CM}$ & Transfersomes & Papaverine hydrochloride & Erectile dysfunction & ------ & 1 & 341 \\
\hline NCM & Liposomes & 9-Nitro-20-(S)-Camptothecin & $\begin{array}{l}\text { Non-small-cell lung cancer and } \\
\text { metastatic endometrial cancer }\end{array}$ & L9NC & 2 & 342,343 \\
\hline NCM & Liposomes & Docetaxel & Solid tumours & ATI-1123 & 1 & 344 \\
\hline NCM & Liposomes & $\begin{array}{c}\text { Growth Factor Receptor Bound } \\
\text { Protein-2 Antisense } \\
\text { Oligonucleotide }\end{array}$ & Leukemia & BP1001 & 1 & 345 \\
\hline
\end{tabular}

\section{Conclusions and Future Perspectives}

The second generation of L-NVs, by complementing liposomes, showing their advantages and overcoming most of their drawbacks, is emerging day-by-day among the large variety of nanocarriers available and it has all the potential to represent a paradigm shift in Nanomedicine. Up to now there are only few non-liposomal L-NVs commercialized or under clinical studies, but their ancestors, liposomes, have already shown the full potential of L-NVs as nanocarriers both for synthetic drugs and biopharmaceuticals delivery, stepping from the lab-bench to the clinical practice. Among the non-liposomal L-NVs developed, 
sphingosomes and virosomes have shown to be the most successful ones by reaching clinical use. Nevertheless, other types of non-liposomal L-NVs such as quatsomes, niosomes, transfersomes and ethosomes have been showing promising in vitro and in vivo results in a variety of applications. Thus, it would be expected that in the near future, the pipeline of Pharmaceutical Industries will be fulfilled by non-liposomal L-NVs drug products to treat many diseases, not only limited to oncology and vaccines which will definitively impose their presence in the market and clinical use. Conventional methods are nowadays predominantly exploited to prepare the commercially available lipid-based drug formulations, yielding final products many times not fully homogeneous, and that can be contaminated to some extent with residual organic solvents. Furthermore, their scale-up from lab scale to the industrial scenario of these multistep processes, in a controlled way, granting high-quality products, is not easy at all, arising as major drawback that limit the translation of these systems from the bench to the bedside. In this frame, CFbased technologies are everyday stepping forward as promising alternatives: their affordable cost, simplicity, high throughputs of L-NVs with controlled physicochemical properties and almost no trace of residual solvents, as well as their great flexibility and easy scalability make them ideal methods for pharmaceutical companies. Taking all of these into consideration, we strongly believe that CF technologies have a bright future in playing an important role in the development and production of improved LNVs drug formulations, and that they will support these outstanding nanocarriers during their rocky way from the preclinical stages, through its translation to clinic phases, and then finally to the market.

\section{Acknowledgements}

This work was financially supported by MINECO (DGI), Spain, grants BE-WELL CTQ2013-40480-R, TERARMET (RTC-2014-2207-1), QUATFORFRAG (RTC-2014-2183-5) and UNDERLIPIDS (RTC-2015-3303-1), and by AGAUR, Generalitat de Catalunya, "Grant 2014SGR-17“. N.G. acknowledges the European Commission (EC) (FP7-PEOPLE-2013-Initial Training Networks (ITN) "NANO2FUN" Project No. 607721) for their Postdoctoral contract. The authors appreciate support from LIPOCELL project financed by CIBERBBN and Praxis Pharmaceuticals and also acknowledge the financial support from Instituto de Salud Carlos III, through "Acciones CIBER". The Networking Research Center on Bioengineering, Biomaterials and Nanomedicine (CIBER-BBN) is an initiative funded by the VI National R\&D\&I Plan 2008-2011, Iniciativa Ingenio 2010, Consolider Program, CIBER Actions and financed by the Instituto de Salud Carlos III with assistance from the European Regional Development Fund.

\section{Notes and references}

J. Wilkinson, Med. Device Technol., 2003, 14, 29-31.

L. Pray and A. Y. Rapporteurs, 2009.

J. M. Martínez-Duart, R. J. Martín-Palma and F. Agulló-Rueda, Nanotechnology for Microelectronics and Optoelectronics, Elsevier

B.V., Amsterdam, 1st edn., 2006.

S. Ponmani, R. Nagarajan and J. Sangwai, J. Nano Res., 2013, 24, 7-15.

O. C. Farokhzad and R. Langer, ACS Nano, 2009, 3, 16-20.

L. Zhang, F. X. Gu, J. M. Chan, A. Z. Wang, R. S. Langer and O. C. Farokhzad, Clin. Pharmacol. Ther., 2008, 83, 761-9.

N. R. Patel, B. S. Pattni, A. H. Abouzeid and V. P. Torchilin, Adv. Drug Deliv. Rev., 2013, 65, 1748-62.

V. P. Torchilin, Nat. Rev. Drug Discov., 2014, 13, 813-27.

S. Mura and P. Couvreur, Adv. Drug Deliv. Rev., 2012, 64, 1394-416.

P. Couvreur and C. Vauthier, Pharm. Res., 2006, 23, 1417-50.

European Science Foundation, Nanomedicine - An ESF-European Medical Research Councils (EMRC) Forward Look Report., Strasbourg cedex, France, 2004.

S. Onoue, S. Yamada and H. K. Chan, Int J Nanomedicine, 2014, 9, 1025-1037.

S. Kumar, D. Bhargava, A. Thakkar and S. Arora, Crit Rev Ther Drug Carr. Syst, 2013, 30, 217-256.

S. Mitragotri, P. A. Burke and R. Langer, Nat. Rev. Drug Discov., 2014, 13, 655-672.

D. Ibraheem, A. Elaissari and H. Fessi, Int. J. Pharm., 2014, 477, 578-589.

J.-S. Lee, J. J. Green, K. T. Love, J. Sunshine, R. Langer and D. G. Anderson, Nano Lett., 2009, 9, 2402.

S. Prakash, M. Malhotra, W. Shao, C. Tomaro-Duchesneau and S. Abbasi, Adv. Drug Deliv. Rev., 2011, 63, 1340-51.

L. Zha, B. Banik and F. Alexis, Soft Matter, 2011, 7, 5908-5916.

N. Nasongkla, E. Bey, J. Ren, H. Ai, C. Khemtong, J. S. Guthi, S.-F. Chin, A. D. Sherry, D. A. Boothman and J. Gao, Nano Lett., 2006, 6, 2427-2430.

T. Ta and T. M. Porter, J. Control. Release, 2013, 169, 112-125.

Y. B. Patil, U. S. Toti, A. Khdair, L. Ma and J. Panyam, Biomaterials, 2009, 30, 859-866.

R. A. Petros and J. M. DeSimone, Nat. Rev. Drug Discov., 2010, 9, 615-627.

S. Hussain, A. Pluckthun, T. M. Allen and U. Zangemeister-Wittke, Mol. Cancer Ther., 2007, 6, 3019-3027.

T. M. Allen and P. R. Cullis, Science (80-. )., 2004, 303, 121-131.

J. Swaminathan and C. Ehrhardt, Expert Opin. Drug Deliv., 2012, 9, 1489-1503. 
D. Kumar Malik, S. Baboota, A. Ahuja, S. Hasan and J. Ali, Curr. Drug Deliv., 2007, 4, 141-151.

a. D. Bangham, J. De Gier and G. D. Greville, Chem. Phys. Lipids, 1967, 1, 225-246.

G. Shi, W. Guo, S. M. Stephenson and R. J. Lee, J. Control. Release, 2002, 80, 309-319.

S. Chono, R. Fukuchi, T. Seki and K. Morimoto, J. Control. Release, 2009, 137, 104-109.

G. P. Mishra, M. Bagui, V. Tamboli and A. K. Mitra, J. Drug Deliv., 2011, 2011, 863734.

S. Mallick and J. S. Choi, J. Nanosci. Nanotechnol., 2014, 14, 755-65.

A. Pantos, D. Tsiourvas, C. M. Paleos and G. Nounesis, Langmuir, 2005, 21, 6696-6702.

D. Liu, F. Liu and Y. K. Song, Biochim. Biophys. Acta, 1995, 1235, 140-146.

M. L. Immordino, F. Dosio and L. Cattel, Int. J. Nanomedicine, 2006, 1, 297-315.

D. C. Drummond, K. Hong, J. W. Park, C. C. Benz and D. B. Kirpotin, Vitam Horm, 2000, 60, 285-332.

S. Geng, B. Yang, G. Wang, G. Qin, S. Wada and J.-Y. Wang, Nanotechnology, 2014, 25, 275103.

Z. Drulis-Kawa and A. Dorotkiewicz-Jach, Int. J. Pharm., 2010, 387, 187-198.

M. Dubois and T. Zemb, Langmuir, 1991, 7, 1352-1360.

F. Caboi and M. Monduzzi, Langmuir, 1996, 12, 3548-3556.

O. H. El-Nesr, S. a. Yahiya and O. N. El-Gazayerly, Saudi Pharm. J., 2010, 18, 217-224.

P. Castagnos, I. Rico-Lattes, M. Blanzat, C. Mauroy, J. Orio, M.-C. Blache, J. Teissie and M.-P. Rols, Mol. Pharm., 2014.

A. Gupta, G. Aggarwal, S. Singla and R. Arora, Sci Pharm, 2012, 80, 1061-1080.

G. P. Kumar and P. Rajeshwarrao, Acta Pharm. Sin. B, 2011, 1, 208-219.

K. Mäder and W. Mehnert, Adv. Drug Deliv. Rev., 2001, 47, 165-96.

M. Jaiswal, R. Dudhe and P. K. Sharma, 3 Biotech, 2015, 5, 123-127.

C. Marianecci, L. Di Marzio, F. Rinaldi, C. Celia, D. Paolino, F. Alhaique, S. Esposito and M. Carafa, Adv. Colloid Interface Sci., 2014, 205, 187-206.

G. Cevc and G. Blume, Biochim. Biophys. Acta-Biomembr., 2001, 1514, 191-205.

A. Paul, G. Cevc and B. K. Bachhawat, Vaccine, 1998, 16, 188-195.

B. M. Discher, Y. Y. Won, D. S. Ege, J. C. Lee, F. S. Bates, D. E. Discher and D. A. Hammer, Science, 1999, 284, 1143-6.

Y. Fan, Y. Liu, J. Xi and R. Guo, J. Colloid Interface Sci., 2011, 360, 148-153.

H. Lomas, I. Canton, S. MacNeil, J. Du, S. P. Armes, A. J. Ryan, A. L. Lewis and G. Battaglia, Adv. Mater., 2007, 19, 4238-4243.

H. Kukula, H. Schlaad, M. Antonietti and S. Förster, J. Am. Chem. Soc., 2002, 124, 1658-63.

B. Guo, Z. Shi, Y. Yao, Y. Zhou and D. Yan, Langmuir, 2009, 25, 6622-6.

S. Gudlur, P. Sukthankar, J. Gao, L. A. Avila, Y. Hiromasa, J. Chen, T. Iwamoto and J. M. Tomich, PLoS One, 2012, 7, e45374.

S. Zhou, C. Burger, B. Chu, M. Sawamura, N. Nagahama, M. Toganoh, U. E. Hackler, H. Isobe, E. Nakamura, H. Tokuyama, S.

Yamago, E. Nakamura, T. Shiraki, Y. Sugiura, S. Yamago, E. Nakamura, H. Tokuyama, S. Yamago, T. Shiraki, Y. Sugiura, A. S.

Bouterine, Y.-Z. An, A. M. Cassell, W. A. Scrivens, J. M. Tour, M. Sawamura, H. likura, E. Nakamura, M. Sawamura, H. likura, T.

Ohama, U. E. Hackler, E. Nakamura, M. Sawamura, H. likura, A. Hirai, E. Nakamura, S. Shinkai, H. likura, S. Mori, M. Sawamura, E. Nakamura, S. W. Provencher, B. Burchard, M. Schmidt and W. H. Stockmayer, Science, 2001, 291, 1944-7.

C. Burger, J. Hao, Q. Ying, H. Isobe, M. Sawamura, E. Nakamura and B. Chu, J. Colloid Interface Sci., 2004, 275, $632-641$.

V. Mohanta, D. Dey, S. Ramakumar and S. Patil, 2015.

M. Antonietti and S. Förster, Adv. Mater., 2003, 15, 1323-1333.

K. Valdés, M. J. Morilla, E. Romero and J. Chávez, Colloids Surfaces B Biointerfaces, 2014, 117, 1-6.

A. Manosroi, P. Wongtrakul, J. Manosroi, H. Sakai, F. Sugawara, M. Yuasa and M. Abe, Colloids Surfaces B Biointerfaces, 2003, 30, 129-138.

M. Ma, Y. Hao, N. Liu, Z. Yin, L. Wang, X. Liang and X. Zhang, Int. J. Nanomedicine, 2012, 7, 3389-98.

D. F. Gaddy, H. Lee, J. Zheng, D. A. Jaffray, T. J. Wickham and B. S. Hendriks, EJNMMI Res., 2015, 5, 24.

R. R. Sawant, N. R. Patel and V. P. Torchilin, Eur. J. Nanomedicine, 2013, 5, 141-158.

L. Di Marzio, C. Marianecci, M. Petrone, F. Rinaldi and M. Carafa, Colloids Surfaces B Biointerfaces, 2011, 82, 18-24.

A. Jesorka and O. Orwar, Annu. Rev. Anal. Chem., 2008, 1, 801-832.

D. A. Balazs, W. Godbey, D. A. Balazs and W. Godbey, J. Drug Deliv., 2011, 2011, 1-12.

E. Elizondo, E. Moreno, I. Cabrera, A. Córdoba, S. Sala, J. Veciana and N. Ventosa, in Progress in Molecular Biology and

Translational Science, 2011, vol. 104, pp. 1-52.

F. Ravar, E. Saadat, M. Gholami, P. Dehghankelishadi, M. Mahdavi, S. Azami and F. A. Dorkoosh, J Control Release, 2016, 229, 1022.

G. Sharma, H. Goyal, K. Thakur, K. Raza and O. P. Katare, Drug Deliv, 2016, 1-11.

E. Ojeda, G. Puras, M. Agirre, J. Zarate, S. Grijalvo, R. Eritja, G. Martinez-Navarrete, C. Soto-Sánchez, A. Diaz-Tahoces, M. AvilesTrigueros, E. Fernández and J. L. Pedraz, Biomaterials, 2016, 77, 267-79.

S. Mahor, A. Rawat, P. K. Dubey, P. N. Gupta, K. Khatri, A. K. Goyal and S. P. Vyas, Int. J. Pharm., 2007, 340, $13-9$.

M. A. Rodriguez, R. Pytlik, T. Kozak, M. Chhanabhai, R. Gascoyne, B. Lu, S. R. Deitcher, J. N. Winter and Marqibo Investigators,

Cancer, 2009, 115, 3475-82.

J. de Jonge, M. Holtrop, J. Wilschut and A. Huckriede, Gene Ther., 2006, 13, 400-11. 
N. Thomas, D. Dong, K. Richter, M. Ramezanpour, S. Vreugde, B. Thierry, P.-J. Wormald and C. A. Prestidge, J. Mater. Chem. B, 2015, 3, 2770-2777.

R. M. Handjani-Vila, A. Ribier, B. Rondot and G. Vanlerberghie, Int. J. Cosmet. Sci., 1979, 1, 303-314.

R. Rajera, K. Nagpal, S. K. Singh and D. N. Mishra, Biol. Pharm. Bull., 2011, 34, 945-953.

S. Moghassemi and A. Hadjizadeh, J Control Release, 2014, 185, 22-36.

V. B. Junyaprasert, V. Teeranachaideekul and T. Supaperm, AAPS PharmSciTech, 2008, 9, 851-859.

S. Moghassemi, E. Parnian, A. Hakamivala, M. Darzianiazizi, M. M. Vardanjani, S. Kashanian, B. Larijani and K. Omidfar, Mater. Sci. Eng. C, 2015, 46, 333-340.

J. N. Israelachvili, D. J. Mitchell and B. W. Ninham, J. Chem. Soc. Faraday Trans. 2, 1976, 72, 1525.

L. Redondo-Morata, M. I. Giannotti and F. Sanz, Langmuir, 2012, 28, 12851-12860.

G. Cevc, Biochemistry, 1991, 30, 7186-7193.

D. Papahadjopoulos, K. Jacobson, S. Nir and I. Isac, Biochim. Biophys. Acta-Biomembr., 1973, 311, 330-348.

J. Y. Fang, C. T. Hong, W. T. Chiu and Y. Y. Wang, Int. J. Pharm., 2001, 219, 61-72.

C. Marianecci, D. Paolino, C. Celia, M. Fresta, M. Carafa and F. Alhaique, J. Control. Release, 2010, 147, 127-35.

K. Ruckmani, V. Sankar and M. Sivakumar, J. Biomed. Nanotechnol., 2010, 6, 43-51.

A. Y. Ozer, S. Turker, S. Colak, M. Korkmaz, E. Kiliç and M. Ozalp, Interv. Med. Appl. Sci., 2013, 5, 122-30.

A. Pardakhty, J. Varshosaz and A. Rouholamini, Int. J. Pharm., 2007, 328, 130-141.

A. B. Shreya, R. S. Managuli, J. Menon, L. Kondapalli, A. R. Hegde, K. Avadhani, P. K. Shetty, M. Amirthalingam, G. Kalthur and S. Mutalik, J. Liposome Res., 2015, 30, 1-12.

S. Duangjit, P. Opanasopit, T. Rojanarata and T. Ngawhirunpat, J. Drug Deliv., 2011, 2011, 418316.

A. A. H. Abdellatif and H. M. Tawfeek, AAPS PharmSciTech, 2015, 1-8.

B. J. Garg, N. K. Garg, S. Beg, B. Singh and O. P. Katare, J Drug Target, 2016, 24, 233-246.

R. Rakesh and K. R. Anoop, J. Pharm. Bioallied Sci., 2012, 4, 333-40.

V. Dubey, D. Mishra, T. Dutta, M. Nahar, D. K. Saraf and N. K. Jain, J. Control. Release, 2007, 123, 148-54.

H. Lv, Z. Zhang, X. Wu, Y. Wang, C. Li, W. Gong, L. Gui and X. Wang, PLoS One, 2016, 11, e0145195.

S. C. Semple, R. Leone, J. Wang, E. C. Leng, S. K. Klimuk, M. L. Eisenhardt, Z.-N. Yuan, K. Edwards, N. Maurer, M. J. Hope, P. R. Cullis and Q.-F. Ahkong, J. Pharm. Sci., 2005, 94, 1024-38.

A. Sharma and S. Arora, ISRN Pharm., 2012, 2012, 873653.

A. H. Salama and M. H. Aburahma, Pharm. Dev. Technol., 2015, 21, 1-10.

S. Verma, A. Bhardwaj, M. Vij, P. Bajpai, N. Goutam and L. Kumar, Artif. cells, nanomedicine, Biotechnol., 2014, 42, 95-101.

V. K. Chatap, P. L. Patil and S. D. Patil, Adv. Pharmacol. Pharm., 2014, 2, 67-76.

Z. R. Zhang and J. X. Wang, Yao Xue Xue Bao, 2001, 36, 771-6.

M. G. Cusi, C. Terrosi, G. G. Savellini, G. Di Genova, R. Zurbriggen and P. Correale, Vaccine, 2004, 22, 735-9.

S. Nallet, M. Amacker, N. Westerfeld, L. Baldi, I. König, D. L. Hacker, C. Zaborosch, R. Zurbriggen and F. M. Wurm, Vaccine, 2009, 27, 6415-9.

S. Kuroda, Q. Liu, J. Jung, M. lijima, N. Yoshimoto, T. Niimi, A. Maturana, S. H. Shin, S.-Y. Jeong, E. K. Choi and M. Somiya, Int. J. Nanomedicine, 2015, Volume 10, 4159.

M. Bomsel, D. Tudor, A.-S. Drillet, A. Alfsen, Y. Ganor, M.-G. Roger, N. Mouz, M. Amacker, A. Chalifour, L. Diomede, G. Devillier, Z. Cong, Q. Wei, H. Gao, C. Qin, G.-B. Yang, R. Zurbriggen, L. Lopalco and S. Fleury, Immunity, 2011, 34, 269-80.

G. Cevc, G. Blume and A. Schatzlein, J. Control. Release, 1997, 45, 211-226.

J.-P. Zhang, Y.-H. Wei, Y. Zhou, Y.-Q. Li and X.-A. Wu, Arch. Pharm. Res., 2012, 35, 109-17.

A. Gupta, Sci. Pharm., 2012, 80, 1061-1080.

G. Cevc, A. Schätzlein and H. Richardsen, Biochim. Biophys. Acta-Biomembr., 2002, 1564, 21-30.

M. Trotta, E. Peira, M. E. Carlotti and M. Gallarate, Int. J. Pharm., 2004, 270, 119-125.

M. Garg, D. Mishra, H. Agashe and N. K. Jain, J. Pharm. Pharmacol., 2006, 58, 459-68.

M. A. Khan, J. Pandit, Y. Sultana, S. Sultana, A. Ali, M. Aqil and M. Chauhan, Drug Deliv, 2015, 22, 795-802.

S. Jain, V. Jain and S. C. Mahajan, Adv. Pharm., 2014, 2014, 1-12.

R. Kesharwani, D. K. Patel, A. Sachan, V. Kumar and B. Mazumdar, Res. J. Top. Cosmet. Sci., 2015, 6, 15.

M. M. A. Elsayed, O. Y. Abdallah, V. F. Naggar and N. M. Khalafallah, Pharmazie, 2007, 62, 133-137.

J. M. López-Pinto, M. L. González-Rodríguez and A. M. Rabasco, Int. J. Pharm., 2005, 298, 1-12.

S. Hua, Front Pharmacol, 2015, 6, 219.

E. Touitou, N. Dayan, L. Bergelson, B. Godin and M. Eliaz, J. Control. Release, 2000, 65, 403-418.

P. Verma and K. Pathak, J. Adv. Pharm. Technol. Res., 2010, 1, 274-82.

E. Touitou, B. Godin and C. Weiss, Drug Dev. Res., 2000, 50, 406-415.

Y.-T. Zhang, L.-N. Shen, Z.-H. Wu, J.-H. Zhao and N.-P. Feng, Int. J. Pharm., 2014, 471, 449-452.

Y.-T. Zhang, L.-N. Shen, J.-H. Zhao and N.-P. Feng, Int. J. Nanomedicine, 2014, 9, 669-78.

D. G. C. D. K. S. S. I. J. C. S. R. Swarnlata Saraf., 2011.

M. S. Webb, T. O. Harasym, D. Masin, M. B. Bally and L. D. Mayer, Br. J. Cancer, 1995, 72, 896-904. 
I. V Zhigaltsev, N. Maurer, Q.-F. Akhong, R. Leone, E. Leng, J. Wang, S. C. Semple and P. R. Cullis, J. Control. Release, 2005, 104, 103-11.

D. Patel, C. Patel and R. Jani, Syst. Rev. Pharm., 2011, 2, 72.

S. Roy and J. Dey, Langmuir, 2003, 19, 9625-9629.

128 S. Roy and J. Dey, Langmuir, 2005, 21, 10362-9.

129 R. R. Nayak, S. Roy and J. Dey, Colloid Polym. Sci., 2006, 285, 219-224.

130 R. Mittal, A. Sharma, S. Arora, R. Mittal, A. Sharma and S. Arora, J. Pharm., 2013, 2013, 1-12.

A. Pandita, P. Sharma, A. Pandita and P. Sharma, ISRN Pharm., 2013, 2013, 1-10.

A. Semalty, M. Semalty, B. S. Rawat, D. Singh and M. S. M. Rawat, Expert Opin. Drug Deliv., 2009, 6, 599-612.

P. Shivanand and P. R. Kinjal Smt B P M, Int. J. PharmTech Res., 2, 627-631.

M. Sharma and N. Meshram, Proc. Int. J. Nanomater. Int J Nanomater Nanotechnol Nanomed S.

M. O. Vaizoglu and P. P. Speiser, Acta Pharm. Suec., 1986, 23, 163-72.

A. Semalty, M. Semalty, D. Singh and M. S. M. Rawat, Acta Pharm., 2009, 59, 335-44.

M. Han, J. Chen, S. Chen and X. Wang, Zhongguo Zhong Yao Za Zhi, 2010, 35, 842-6.

J. Almeida, D. C. Edwards, C. Brand and T. Heath, Lancet, 1975, 306, 899-901.

J. Shoji, Y. Tanihara, T. Uchiyama and A. Kawai, Microbiol. Immunol., 2004, 48, 163-174.

K. Sasaki, K. Kogure, S. Chaki, Y. Nakamura, R. Moriguchi, H. Hamada, R. Danev, K. Nagayama, S. Futaki and H. Harashima, Anal. Bioanal. Chem., 2008, 391, 2717-2727.

M. Owais and C. M. Gupta, Eur. J. Biochem., 2000, 267, 3946-3956.

Y. Kaneda, Adv. Drug Deliv. Rev., 2000, 43, 197-205.

R. Glück and I. . Metcalfe, Vaccine, 2003, 21, 611-615.

144 Y. Mohammadzadeh, S. Gholami, N. Rasouli, S. Sarrafzadeh, N. S. Seyed Tabib, M. H. Samiee Aref, A. Abdoli, P. Biglari, F. Fotouhi, B. Farahmand, M. Tavassoti Kheiri and A. Jamali, J. Liposome Res., 2016, 1-7.

145 W. Z. Zhou, D. S. Hoon, S. K. Huang, S. Fujii, K. Hashimoto, R. Morishita and Y. Kaneda, Hum. Gene Ther., 1999, 10, $2719-24$. Pediatr. Infect. Dis. J., 2004, 23, 300-6.

147 L. Ferrer-Tasies, E. Moreno-Calvo, M. Cano-Sarabia, M. Aguilella-Arzo, A. Angelova, S. Lesieur, S. Ricart, J. Faraudo, N. Ventosa and J. Veciana, Langmuir, 2013, 29, 6519-6528.

148 M. Cano-Sarabia, A. Angelova, N. Ventosa, S. Lesieur and J. Veciana, J. Colloid Interface Sci., 2010, 350, $10-15$.

149 E. Elizondo, J. Larsen, N. S. Hatzakis, I. Cabrera, T. Bjørnholm, J. Veciana, D. Stamou and N. Ventosa, J. Am. Chem. Soc., 2012, 134, 1918-1921.

150 L. Ferrer-Tasies, Universitat Autònoma de Barcelona, 2016.

151 S. Azarmi, W. H. Roa and R. Löbenberg, Adv. Drug Deliv. Rev., 2008, 60, 863-75.

152 T. Kubo, T. Sugita, S. Shimose, Y. Nitta, Y. Ikuta and T. Murakami, Int. J. Oncol., 2000, 17, 309-15.

153 R. R. Sawant and V. P. Torchilin, .

154 S. T. Larsen, H. Verder and G. D. Nielsen, Basic Clin. Pharmacol. Toxicol., 2012, 110, 537-43.

H. Lv, S. Zhang, B. Wang, S. Cui and J. Yan, J. Control. Release, 2006, 114, 100-109.

H. Y. Xue, S. Liu and H. L. Wong, Nanomedicine (Lond)., 2014, 9, 295-312.

Y. P. Patil and S. Jadhav, Chem. Phys. Lipids, 2014, 177, 8-18.

158 P. R. Karn, W. Cho and S.-J. Hwang, Nanomedicine, 2013, 8, 1529-1548.

159 L. A. Meure, N. R. Foster and F. Dehghani, AAPS PharmSciTech, 2008, 9, 798-809.

160 F. Szoka and D. Papahadjopoulos, Proc. Natl. Acad. Sci. U. S. A., 1978, 75, 4194-8.

161 N. Düzgünes, Methods Enzymol., 2003, 367, 23-7.

164 N. Berger, A. Sachse, J. Bender, R. Schubert and M. Brandl, Int. J. Pharm., 2001, 223, 55-68.

R. C.

166 D. Bachmann, M. Brandl and G. Gregoriadis, Int. J. Pharm., 1993, 91, 69-74.

167 E. Pupo, A. Padrón, E. Santana, J. Sotolongo, D. Quintana, S. Dueñas, C. Duarte, M. C. de la Rosa and E. Hardy, J. Control. Release, 2005, 104, 379-96.

168 A. D. Bangham, M. M. Standish and J. C. Watkins, J. Mol. Biol., 1965, 13, 238-IN27.

169 R. R. C. New, in Liposomes: a practical approach, ed. R. R. C. New, New York: Oxford University Press, 1990.

170 J. P. Reeves and R. M. Dowben, J. Cell. Physiol., 1969, 73, 49-60.

171 D. W. Deamer, Ann. N. Y. Acad. Sci., 1978, 308, 250-8.

172 H. Schieren, S. Rudolph, M. Finkelstein, P. Coleman and G. Weissmann, Biochim. Biophys. Acta, 1978, 542, $137-53$.

173 H. Alpes, K. Allmann, H. Plattner, J. Reichert, R. Rick and S. Schulz, Biochim. Biophys. Acta-Biomembr., 1986, 862, $294-302$.

174 H. G. Enoch and P. Strittmatter, Proc. Natl. Acad. Sci. U. S. A., 1979, 76, 145-9. 
J. R. Philippot, S. Mutaftschiev and J. P. Liautard, Biochim. Biophys. Acta, 1985, 821, 79-84.

E. Elizondo, J. Veciana and N. Ventosa, Nanomedicine, 2012, 7, 1391-1408.

K. Byrappa, S. Ohara and T. Adschiri, Adv. Drug Deliv. Rev., 2008, 60, 299-327.

C. C. Beh, R. Mammucari and N. R. Foster, Langmuir, 2014, 30, 11046-11054.

C. C. Beh, R. Mammucari and N. R. Foster, Chem. Eng. J., 2012, 188, 1-14.

S. Kunastitchai, L. Pichert, N. Sarisuta and B. W. Müller, Int. J. Pharm., 2006, 316, 93-101.

K. Otake, T. Imura, H. Sakai and M. Abe, Langmuir, 2001, 17, 3898-3901.

I. Kikic and P. Sist, in Supercritical Fluids, Springer Netherlands, Dordrecht, 2000, pp. 291-306.

T. P. Castor, 1994.

T. P. Castor and L. Chu, 1998.

T. P. Castor, 1996.

L. Chu and T. P. Castor, 1996.

T. P. Castor, Curr. Drug Deliv., 2005, 2, 329-40.

T. P. Castor, 2010.

L. Frederiksen, K. Anton, P. van Hoogevest, H. R. Keller and H. Leuenberger, J. Pharm. Sci., 1997, 86, 921-8.

L. Frederiksen, K. Anton and P. van Hoogevest, 1997.

L. Frederiksen, K. Anton, B. J. Barratt, P. Van Hoogevest and H. Leuenberger, in 3rd International Symposium on Supercritical Fluids. vol. 3, Strasbourg, France, 1994, pp. 235-240.

192 K. Aburai, N. Yagi, Y. Yokoyama, H. Okuno, K. Sakai, H. Sakai, K. Sakamoto and M. Abe, J. Oleo Sci., 2011, 60, $209-15$.

193 K. Otake, T. Shimomura, T. Goto, T. Imura, T. Furuya, S. Yoda, Y. Takebayashi, H. Sakai and M. Abe, Langmuir, 2006, 22, 25432550.

194 M. Cano-Sarabia, N. Ventosa, S. Sala, C. Patiño, R. Arranz and J. Veciana, Langmuir, 2008, 24, $2433-2437$.

195 I. Cabrera, E. Elizondo, O. Esteban, J. L. Corchero, M. Melgarejo, D. Pulido, A. Córdoba, E. Moreno, U. Unzueta, E. Vazquez, I. Abasolo, S. Schwartz, A. Villaverde, F. Albericio, M. Royo, M. F. García-Parajo, N. Ventosa and J. Veciana, Nano Lett., 2013, 13, 3766-74.

I. Cabrera, I. Abasolo, J. L. Corchero, E. Elizondo, P. R. Gil, E. Moreno, J. Faraudo, S. Sala, D. Bueno, E. González-Mira, M. Rivas, M. Melgarejo, D. Pulido, F. Albericio, M. Royo, A. Villaverde, M. F. García-Parajo, S. Schwartz, N. Ventosa and J. Veciana, Adv. Healthc. Mater., 2016, 5, 829-840.

197 L. A. Meure, The Development of a Novel Process for the Formation of Liposomes: Depressurisation of an Expanded Solution Into Aqueous Media (DESAM), University of New South Wales, 2004.

198 L. A. Meure, R. Knott, N. R. Foster and F. Dehghani, Langmuir, 2009, 25, 326-337.

199 V. Krukonis, in AICHE annual Fall Meeting, San Francisco, CA, USA, 1984, p. paper $140 f$.

200 D. W. Matson, J. L. Fulton, R. C. Petersen and R. D. Smith, Ind. Eng. Chem. Res., 1987, 26, $2298-2306$.

201 Z. Wen, B. Liu, Z. Zheng, X. You, Y. Pu and Q. Li, Chem. Eng. Res. Des., 2010, 88, 1102-1107.

202

203

W. Zhang, Y. Sun, Y. Li, R. Shen, H. Ni and D. Hu, Artif. Cells. Blood Substit. Immobil. Biotechnol., 2012, 40, 62-5.

C. Magnan, E. Badens, N. Commenges and G. Charbit, J. Supercrit. Fluids, 2000, 19, 69-77.

S. Naik, D. Patel, N. Surti and A. Misra, J. Supercrit. Fluids, 2010, 54, 110-119.

S. Naik, D. Patel, K. Chuttani, A. K. Mishra and A. Misra, Nanomedicine, 2012, 8, 951-62.

L. Lesoin, C. Crampon, O. Boutin and E. Badens, J. Supercrit. Fluids, 2011, 60, 51-62.

L. Lesoin, C. Crampon, O. Boutin and E. Badens, J. Supercrit. Fluids, 2011, 57, 162-174.

2011.

F. Xia, H. Jin, Y. Zhao and X. Guo, J. Microencapsul., 2012, 29, 21-9.

W. C. H.-J. P. J.-S. P. S.-J. H. Pankaj Ranjan Karn, Int. J. Nanomedicine, 2013, 8, 365.

U. S. Kadimi, D. R. Balasubramanian, U. R. Ganni, M. Balaraman and V. Govindarajulu, Nanomedicine, 2007, 3, 273-80.

T. Imura, T. Gotoh, K. Otake, S. Yoda, Y. Takebayashi, S. Yokoyama, H. Takebayashi, H. Sakai, M. Yuasa and M. Abe, Langmuir, 2003, 19, 2021-2025.

213 T. Imura, K. Otake, S. Hashimoto, T. Gotoh, M. Yuasa, S. Yokoyama, H. Sakai, J. F. Rathman and M. Abe, Colloids Surfaces B Biointerfaces, 2003, 27, 133-140.

214 S. Sala, E. Elizondo, E. Moreno, T. Calvet, M. A. Cuevas-Diarte, N. Ventosa and J. Veciana, Cryst. Growth Des., $2010,10,1226-1232$.

215 S. Sala, A. Córdoba, E. Moreno-Calvo, E. Elizondo, M. Muntó, P. E. Rojas, M. À. Larrayoz, N. Ventosa and J. Veciana, Cryst. Growth Des., 2012, 12, 1717-1726.

216 L. Zhao and F. Temelli, J. Supercrit. Fluids, 2015, 100, 110-120.

217 B. Yu, R. J. Lee and L. J. Lee, Methods Enzymol., 2009, 465, 129-41.

218 E. Kastner, R. Kaur, D. Lowry, B. Moghaddam, A. Wilkinson and Y. Perrie, Int. J. Pharm., 2014, 477, 361-8.

219 A. Jahn, J. E. Reiner, W. N. Vreeland, D. L. DeVoe, L. E. Locascio and M. Gaitan, J. Nanoparticle Res., $2008,10,925-934$.

220 X. Hou, Y. Hu, A. Grinthal, M. Khan and J. Aizenberg, Nature, 2015, 519, 70-73.

221 X. Hou, Adv. Mater., 2016.

222 A. Jahn, W. N. Vreeland, M. Gaitan and L. E. Locascio, J. Am. Chem. Soc., 2004, 126, $2674-2675$. 
A. Jahn, W. N. Vreeland, D. L. DeVoe, L. E. Locascio and M. Gaitan, Langmuir, 2007, 23, 6289-93.

Y. Yang, J. Wang, H. Shigematsu, W. Xu, W. M. Shih, J. E. Rothman and C. Lin, 2016.

P. Li, D. Liu, L. Miao, C. Liu, X. Sun, Y. Liu and N. Zhang, Int. J. Nanomedicine, 2012, 7, 925-39.

Y. Dong, Y. Sun, L. Wang, D. Wang, T. Zhou, Z. Yang, Z. Chen, Q. Wang, Q. Fan and D. Liu, Angew. Chemie Int. Ed., 2014, 53, 26072610.

227 S. D. Perrault and W. M. Shih, ACS Nano, 2014, 8, 5132-5140.

228 T. Wang, N. Wang, T. Wang, W. Sun and T. Li, Chem. Phys. Lipids, 2011, 164, 151-157.

229 T. Wang, N. Wang, X. Jin, K. Zhang and T. Li, J. Liposome Res., 2009, 19, 231-240.

230 T. Wang, Y. Deng, Y. Geng, Z. Gao, J. Zou and Z. Wang, 2006.

231 D.-G. Yu, C. Branford-White, G. R. Williams, S. W. A. Bligh, K. White, L.-M. Zhu and N. P. Chatterton, Soft Matter, 2011, 7, 82398247.

232 A. Wicki, D. Witzigmann, V. Balasubramanian and J. Huwyler, J Control Release, 2015, 200, 138-157.

233 Phrma, 2015 Report: Medicines in Development to Treat Cancer, 2015.

F. N. Carlesso, R. S. Araujo, L. L. Fuscaldi, S. E. Mendes Miranda, D. Rubello, C. S. Teixeira, D. C. Dos Reis, E. A. Leite, J. N. Silveira, S.

O. Fernandes, G. D. Cassali, M. C. de Oliveira, P. M. Colletti, A. L. de Barros and V. N. Cardoso, Nucl Med Commun, 2016.

F. Ravar, E. Saadat, P. D. Kelishadi and F. A. Dorkoosh, J Liposome Res, 2015, 1-13.

Y. (Chezy) Barenholz, J. Control. Release, 2012, 160, 117-134.

G. Haran, R. Cohen, L. K. Bar and Y. Barenholz, Biochim. Biophys. Acta, 1993, 1151, 201-15.

Z. Sezgin-Bayindir, A. Onay-Besikci, N. Vural and N. Yuksel, J Microencapsul, 2013, 30, 796-804.

S. Jain, D. Kumar, N. K. Swarnakar and K. Thanki, Biomaterials, 2012, 33, 6758-6768.

S. Jain, S. R. Patil, N. K. Swarnakar and A. K. Agrawal, Mol Pharm, 2012, 9, 2626-2635.

X. Yu, L. Du, Y. Li, G. Fu and Y. Jin, Biomed Pharmacother, 2015, 73, 6-11.

I. A. Alvi, J. Madan, D. Kaushik, S. Sardana, R. S. Pandey and A. Ali, Anticancer Drugs, 2011, 22, 774-782.

J. F. Marier, J. L. Brazier, J. Lavigne and M. P. Ducharme, J Antimicrob Chemother, 2003, 52, 247-252.

J. F. Marier, J. Lavigne and M. P. Ducharme, Antimicrob Agents Chemother, 2002, 46, 3776-3781.

M. Alipour, M. Halwani, A. Omri and Z. E. Suntres, Int J Pharm, 2008, 355, 293-298.

S. P. Vyas, S. Quraishi, S. Gupta and K. S. Jaganathan, Int J Pharm, 2005, 296, 12-25.

T. R. Desai, R. E. Hancock and W. H. Finlay, Eur J Pharm Sci, 2003, 20, 459-467.

J. P. Wong, H. Yang, K. L. Blasetti, G. Schnell, J. Conley and L. N. Schofield, J Control Release, 2003, 92, 265-273.

S. Chono, T. Tanino, T. Seki and K. Morimoto, J Control Release, 2008, 127, 50-58.

L. G. Sweeney, Z. Wang, R. Loebenberg, J. P. Wong, C. F. Lange and W. H. Finlay, Int J Pharm, 2005, 305, 180-185.

D. Cipolla, H. Wu, I. Gonda and H.-K. Chan, AAPS PharmSciTech, 2014, 15, 1218-27.

H. Pinto-Alphandary, A. Andremont and P. Couvreur, Int J Antimicrob Agents, 2000, 13, 155-168.

P. R. Gangadharam, D. R. Ashtekar, D. L. Flasher and N. Düzgüneş, Antimicrob Agents Chemother, 1995, 39, 725-730.

M. A. Vladimirsky and G. A. Ladigina, Biomed Pharmacother, 1982, 36, 375-377.

H. Tomioka, H. Saito, K. Sato and T. Yoneyama, Am Rev Respir Dis, 1991, 144, 575-579.

E. A. Petersen, J. B. Grayson, E. M. Hersh, R. T. Dorr, S. M. Chiang, M. Oka and R. T. Proffitt, J Antimicrob Chemother, 1996, 38, 819-828.

S. Leitzke, W. Bucke, K. Borner, R. Müller, H. Hahn and S. Ehlers, Antimicrob Agents Chemother, 1998, 42, 459-461.

C. E. Swenson, M. C. Popescu and R. S. Ginsberg, Crit Rev Microbiol, 1988, 15 Suppl 1, S1-31.

S. P. Vyas, M. E. Kannan, S. Jain, V. Mishra and P. Singh, Int J Pharm, 2004, 269, 37-49.

M. M. Elsayed, O. Y. Abdallah, V. F. Naggar and N. M. Khalafallah, Int J Pharm, 2007, 332, 1-16.

G. Cevc and U. Vierl, J Control Release, 2010, 141, 277-299.

I. A. Alsarra, A. Y. Hamed, F. K. Alanazi and G. M. El Maghraby, in Drug Delivery to the Central Nervous System, ed. K. K. Jain, Springer Science+Business Media, LLC, 2010, vol. 45, pp. 175-203.

S. Duangjit, P. Opanasopit, T. Rojanarata and T. Ngawhirunpat, AAPS PharmSciTech, 2013, 14, 133-140.

S. Ghanbarzadeh and S. Arami, Biomed Res Int, 2013, 2013, 616810.

S. Mahmood, M. Taher and U. K. Mandal, Int J Nanomedicine, 2014, 9, 4331-4346.

D. Singodia, G. K. Gupta, A. Verma, V. Singh, P. Shukla, P. Misra, S. Sundar, A. Dube and P. R. Mishra, J Biomed Nanotechnol, 2010,

6, 293-302.

R. Rajan and D. T. Vasudevan, J Adv Pharm Technol Res, 2012, 3, 112-116.

M. Yusuf, V. Sharma and K. Pathak, Int J Pharm Investig, 2014, 4, 119-130.

T. A. Ahmed, K. M. El-Say, B. M. Aljaeid, U. A. Fahmy and F. I. Abd-Allah, Int J Pharm, 2016, 500, 245-254. 
S. Shelke, S. Shahi, S. Jalalpure and D. Dhamecha, J Liposome Res, 2016, 1-11.

V. Garg, H. Singh, A. Bhatia, K. Raza, S. K. Singh, B. Singh and S. Beg, AAPS PharmSciTech, 2016.

S. Babaie, S. Ghanbarzadeh, S. Davaran, M. Kouhsoltani and H. Hamishehkar, Adv Pharm Bull, 2015, 5, 549-556.

M. Bragagni, N. Mennini, F. Maestrelli, M. Cirri and P. Mura, Drug Deliv, 2012, 19, 354-361.

C. Marianecci, L. Di Marzio, F. Rinaldi, C. Celia, D. Paolino, F. Alhaique, S. Esposito and M. Carafa, Adv Colloid Interface Sci, 2014, 205, 187-206.

280 Q. Li, Z. Li, W. Zeng, S. Ge, H. Lu, C. Wu, L. Ge, D. Liang and Y. Xu, Eur J Pharm Sci, 2014, 62, 115-123.

281

290 M. Niu, Y. Lu, L. Hovgaard, P. Guan, Y. Tan, R. Lian, J. Qi and W. Wu, Eur. J. Pharm. Biopharm., $2012,81,265-272$.

291 G. D. Reynolds, H. J. Baker and R. H. Reynolds, Nature, 1978, 275, 754-755.

292 G. Cevc, D. Gebauer, J. Stieber, A. Schätzlein and G. Blume, Biochim. Biophys. Acta, 1998, 1368, 201-15.

293 D. I. J. Morrow, P. A. McCarron, A. D. Woolfson and R. F. Donnelly, Open Drug Deliv. J. , 1.

294 R. \& P. A. Kumar, Trop. J. Pharm. Res., 6, 633-644.

295 K. Rai, Y. Gupta, A. Jain and S. K. Jain, PDA J. Pharm. Sci. Technol., 62, 362-79.

296 ProNAi Therapeutics, Inc. PNT2258 for Treatment of Patients With Richter's Transformation (Brighton). NCT02378038. https://clinicaltrials.gov/, .

297 ProNAi Therapeutics, Inc. Study of PNT2258 for Treatment of Relapsed or Refractory Non-Hodgkin's Lymphoma. NCT01733238. https://clinicaltrials.gov/, .

298 Insmed Incorporated. Study to Evaluate Arikayce ${ }^{T M}$ in CF Patients With Chronic Pseudomonas Aeruginosa Infections. NCT01315678. https://clinicaltrials.gov/, .

299 University of Pittsburgh. Safety Study of S-CKD602 in Patients With Advanced Malignancies. NCT00177281. https://clinicaltrials.gov/, .

300 LiPlasome Pharma. Phase I Study to Evaluate the Safety and Tolerability of LiPlaCis in Patients With Advanced or Refractory Tumours (LiPlaCis). NCT01861496. https://clinicaltrials.gov/, .

301 New York University School of Medicine. Liposomal Cisplatin in Treating Patients With Recurrent Ovarian Cancer. NCT00004083. https://clinicaltrials.gov/, .

302 Aronex Pharmaceuticals. A Safety and Effectiveness Study of Aroplatin in Patients With Advanced Solid Malignancies. NCT00057395. https://clinicaltrials.gov/, .

303 INSYS Therapeutics Inc. Study to Determine the Maximum Tolerated Dose of LErafAON in Patients With Advanced Solid Tumors. NCT00024661. https://clinicaltrials.gov/, .

304 SignPath Pharma, Inc. A Phase IB Dose Escalation Study of Lipocurc in Patients With Cancer. NCT02138955. https://clinicaltrials.gov/, .

305 Celator Pharmaceuticals. Phase III Study of CPX-351 Versus 7+3 in Patients 60-75 Years Old With Untreated High Risk (Secondary) Acute Myeloid Leukemia. NCT01696084. https://clinicaltrials.gov/, .

306 Fred Hutchinson Cancer Research Center. Liposomal Cytarabine-Daunorubicin CPX-351 in Treating Patients With Untreated Myelodysplastic Syndrome or Acute Myeloid Leukemia. NCT01804101. https://clinicaltrials.gov/, .

307 INSYS Therapeutics Inc. Efficacy and Safety Study of LE-DT to Treat Locally Advanced or Metastatic Pancreatic Cancer. NCT01186731. https://clinicaltrials.gov/, .

308 Celsion. Study of ThermoDox With Standardized Radiofrequency Ablation (RFA) for Treatment of Hepatocellular Carcinoma (HCC) (OPTIMA). NCT02112656. https://clinicaltrials.gov/, .

309 Celsion. Phase 1/2 Study of ThermoDox With Approved Hyperthermia in Treatment of Breast Cancer Recurrence at the Chest Wall (DIGNITY). NCT00826085. https://clinicaltrials.gov/, .

310 BBB-Therapeutics B.V. An Open-label, Phase I/Ila, Dose Escalating Study of 2B3-101 in Patients With Solid Tumors and Brain Metastases or Recurrent Malignant Glioma. NCT01386580. https://clinicaltrials.gov/, .

311 Merrimack Pharmaceuticals. MM-302 Plus Trastuzumab vs. Chemotherapy of Physician's Choice Plus Trastuzumab in HER2-Positive Locally Advanced/Metastatic Breast Cancer Patients (HERMIONE). NCT02213744, .

312 ImmunoVaccine Technologies, Inc. A Phase I Safety Study of a Cancer Vaccine to Treat HLA-A2 Positive Advanced Stage Ovarian, Breast and Prostate Cancer. NCT01095848. https://clinicaltrials.gov/, .

313 Diasome Pharmaceuticals. Study of Two Doses of Oral HDV-Insulin and Placebo With Background Metformin Treatment in Patients 
With Type 2 Diabetes Mellitus. NCT00814294. https://clinicaltrials.gov/, .

314 Celator Pharmaceuticals. Multicenter Study Of CPX-1 (Irinotecan HCl: Floxuridine) Liposome Injection In Patients With Advanced Colorectal Cancer. NCT00361842. https://clinicaltrials.gov/, .

315 Astellas Pharma Inc. Study of OSI-211 vs. Topotecan in Patients With Relapsed Epithelial Ovarian Cancer. NCT00046800. https://clinicaltrials.gov/, .

316 Astellas Pharma Inc. Efficacy and Safety Study of OSI-211 (Liposomal Lurtotecan) to Treat Recurrent Small Cell Lung Cancer. NCT00046787. https://clinicaltrials.gov/, .

317 Mirna Therapeutics, Inc. A Multicenter Phase I Study of MRX34, MicroRNA miR-RX34 Liposomal Injection. NCT01829971. https://clinicaltrials.gov/, .

318 Lipomedix Pharmaceuticals Inc. Intravenously Administered Pegylated Liposomal Mitomycin-C Lipid-based Prodrug (PROMITIL) in Cancer Patients With Solid Tumors. NCT01705002. https://clinicaltrials.gov/, .

319 INSYS Therapeutics Inc. Study of Liposome Encapsulated Mitoxantrone (LEM) in Patients With Advanced Cancer. NCT00024492. https://clinicaltrials.gov/, .

320 SynerGene Therapeutics, Inc. Phase II Study of Combined Temozolomide and SGT-53 for Treatment of Recurrent Glioblastoma. NCT02340156. https://clinicaltrials.gov/, .

321 SynerGene Therapeutics, Inc. Study of Combined SGT-53 Plus Gemcitabine/Nab-Paclitaxel for Metastatic Pancreatic Cancer. NCT02340117. https://clinicaltrials.gov/, .

322 INSYS Therapeutics Inc. Efficacy and Safety Study of LEP-ETU to Treat Metastatic Breast Cancer. NCT01190982. https://clinicaltrials.gov/, .

323 MediGene. A Trial Evaluating the Pharmacokinetics and Mode of Action of EndoTAG ${ }^{\circledR}-1$ in Tumor Patients With Hepatic Metastases. NCT00542048. https://clinicaltrials.gov/, .

324 Jules Bordet Institute. Trial of Neoadjuvant EndoTAG-1 in Combination With Paclitaxel in HER2-negative Breast Cancer (EndoTAG1). NCT01537536. $v$, .

325 Leiden University Medical Center. The LIPMAT Study: Liposomal Prednisolone to Improve Hemodialysis Fistula Maturation. NCT02495662. https://clinicaltrials.gov/, .

326 Sun Pharma Global FE. Evaluate The Efficacy And Safety Of Intravenous Pegylated Liposomal Prednisolone Sodium Phosphate Compared With Intramuscular Injection Of Methylprednisolone Acetate In Subjects With Active Rheumatoid Arthritis. NCT02534896. https://, .

327 SynerGene Therapeutics, Inc. A Phase I Study of Systemic Gene Therapy With SGT-94 in Patients With Solid Tumors (SGT94-01). NCT01517464. https://clinicaltrials.gov/, .

328 ImmunoVaccine Technologies, Inc. A Study to Evaluate the Safety and Reactogenicity of DPX-RSV(A), a Respiratory Syncytial Virus Vaccine. NCT02472548. https://clinicaltrials.gov/, .

329 Silence Therapeutics GmbH. Study With Atu027 in Patients With Advanced Solid Cancer. NCT00938574. https://clinicaltrials.gov/,

330 Silence Therapeutics GmbH. Atu027 Plus Gemcitabine in Advanced or Metastatic Pancreatic Cancer (Atu027-I-02). NCT01808638. https://clinicaltrials.gov/, .

331 Alliance for Clinical Trials in Oncology. Liposomal SN-38 in Treating Patients With Metastatic Colorectal Cancer. NCT00311610. https://clinicaltrials.gov/, .

332 ImmunoVaccine Technologies, Inc. Phase 1-2 Study of a Cancer Vaccine to Treat Patients With Advanced Stage Ovarian, Fallopian or Peritoneal Cancer. NCT01416038. https://clinicaltrials.gov/, .

333 Eastern Cooperative Oncology Group. BLP25 Liposome Vaccine and Bevacizumab After Chemotherapy and Radiation Therapy in Treating Patients With Newly Diagnosed Stage IIIA or Stage IIIB Non-Small Cell Lung Cancer. NCT00828009.

https://clinicaltrials.gov/, .

334 EMD Serono. Tecemotide (L-BLP25) in Prostate Cancer. NCT01496131. https://clinicaltrials.gov/, .

335 Merck KGaA. Tecemotide (L-BLP25) in Rectal Cancer (SPRINT). NCT01507103. https://clinicaltrials.gov/, .

336 OSI Pharmaceuticals. Phase II Study of Single Agent OSI-7904L in Patients With Gastric or Gastroesophageal (GEJ) Cancer. NCT00073502. https://clinicaltrials.gov/, .

337 OSI Pharmaceuticals. Phase I Study of Cisplatin Plus OSI-7904L in Patients With Solid Tumors. NCT00116896. https://clinicaltrials.gov/, .

338 Gynecologic Oncology Group. Radiation Therapy and Chemotherapy in Treating Patients With Locally Advanced Cervical Cancer. NCT00054444. https://clinicaltrials.gov/, .

339 Spectrum Pharmaceuticals, Inc. Topotecan Liposomes Injection for Small Cell Lung Cancer (SCLC), Ovarian Cancer and Other Advanced Solid Tumors. NCT00765973. https://clinicaltrials.gov/, .

340 G. Batist, A. Tolcher, J. Sarantopoulos, K. Sankhala, J. Fontanilla, B. Lu, G. Choy and S. Deitcher, Mol. Cancer Ther., 2007, 6, A150A150.

341 H. Salem, S. Attia, H. Abdelmohsen and M. Ali, Drug Des. Devel. Ther., 2015, 9, 2431-2447.

342 University of New Mexico. Study of Aerosolized Liposomal 9-Nitro-20 (S)-Camptothecin (L9NC). NCT00250068. https://clinicaltrials.gov/, .

343 University of New Mexico. Phase II Study of Aerosolized Liposomal 9-Nitro-20 (S)- Camptothecin (L9NC). NCT00249990. 
https://clinicaltrials.gov/, .

Azaya Therapeutics, Inc. Safety Study of a Liposomal Docetaxel Formulation in Patients With Solid Tumors Who Have Failed Previous Therapies. NCT01041235. https://clinicaltrials.gov/, .

345 Bio-Path Holdings, Inc. Clinical Trial of BP1001 (L-Grb-2 Antisense Oligonucleotide) in CML, AML, ALL \&amp; MDS. NCT01159028. https://clinicaltrials.gov/, . 